Article

\title{
Sustainable Sports Tourism Performance Assessment Using Grey-Based Hybrid Model
}

\author{
Chin-Cheng Yang ${ }^{1,2}$, Chih-Chien Shen ${ }^{3, * \mathbb{C}}$, Yu-Sheng Lin ${ }^{4}$, Huai-Wei Lo ${ }^{5,6, *(\mathbb{D})}$ and Jia-Zhi Wu ${ }^{1}$ \\ 1 Department of Leisure Services Management, Chaoyang University of Technology, Taichung 413310, Taiwan; \\ yccheng@cyut.edu.tw (C.-C.Y.); a098152499985@gmail.com (J.-Z.W.) \\ 2 School of Technological and Vocational Education, National Yunlin University of Science and Technology, \\ Yunlin 64002, Taiwan \\ 3 Institute of Physical Education and Health, Yulin Normal University, Yulin 537000, China \\ 4 Physical Education Office, Chaoyang University of Technology, Taichung 413310, Taiwan; \\ lin3117@cyut.edu.tw \\ 5 Department of Industrial Engineering and Management, Chaoyang University of Technology, \\ Taichung 413310, Taiwan \\ 6 Department of Industrial Engineering and Management, National Taipei University of Technology, \\ Taipei 10608, Taiwan \\ * Correspondence: g169168@gmail.com (C.-C.S.); w110168888@gmail.com or t105749006@ntut.org.tw (H.-W.L.)
}

check for updates

Citation: Yang, C.-C.; Shen, C.-C.; Lin, Y.-S.; Lo, H.-W.; Wu, J.-Z. Sustainable Sports Tourism Performance Assessment Using Grey-Based Hybrid Model. Sustainability 2021, 13, 4214. https:// doi.org/10.3390/su13084214

Academic Editor: Alon Gelbman

Received: 12 March 2021

Accepted: 7 April 2021

Published: 10 April 2021

Publisher's Note: MDPI stays neutral with regard to jurisdictional claims in published maps and institutional affiliations.

Copyright: (c) 2021 by the authors. Licensee MDPI, Basel, Switzerland. This article is an open access article distributed under the terms and conditions of the Creative Commons Attribution (CC BY) license (https:// creativecommons.org/licenses/by/ $4.0 /)$.
Abstract: The development of sports tourism is gaining momentum around the world, with many tourism industries combining sports events and programs to attract more domestic and overseas customers to promote economic and culture. Sustainability awareness has been gaining attention from many international organizations, resulting in the rise of sports tourism that incorporates sustainability. Therefore, the development of a valid and applicable sustainable sports tourism (SST) assessment model is an important task. In this study, a hybrid Multiple Attribute Decision-Making (MADM) model is proposed to measure the development performance of SST. The aims of this study include developing a SST assessment framework, identifying the mutual influential relationships among attributes, generating attribute influence weights, and calculating the performance of the evaluated items. The proposed model is divided into three stages. First, a cause-and-effect diagram is generated using the Grey Decision-Making Trial and Evaluation Laboratory (GDEMATEL) to describe the interactions and feedback among the attributes. Then, the GDEMATEL-based Analytic Network Process (GDANP) is applied to generate the influence weights of the attributes and their rankings. Finally, the expanded Probability-based Grey Relational Analysis (expanded PGRA) was applied to calculate the performance of the evaluated items and to determine the gap between evaluated items and the aspiration level. This study improves the original PGRA technique by introducing the concept of aspiration level into the PGRA calculation process, thereby replacing the traditional concept of "relative satisfaction" with "aspiration level". In addition, the expanded PGRA can assess a single rated item without being limited to at least two items. We used the Sun Moon Lake Scenic Area in Taiwan as a model demonstration. The results show that the top three attributes that need to be strengthened are disease prevention and treatment, local social welfare and protection, and sports diversity. In the Sun Moon Lake, intersection control should be set up to ensure the health status of visitors and local residents. In addition to epidemic prevention, more measures and behaviors should be developed to deal with tourism diseases. We suggested that subsidies be provided to local residents to rebuild the fences around their homes to avoid disturbances caused by the influx of tourists. Moreover, the local government can create more sports events with special characteristics that can attract tourists to come again and again.

Keywords: sustainability; sustainable sports tourism; MADM; DANP; GRA; grey theory 


\section{Introduction}

The ease of transportation and the advancement of communication technologies have led to increasing demand for tourism [1]. In some countries, the development of tourism is considered an effective way to reduce and even alleviate poverty. Tourism provides many job opportunities different from traditional manufacturing, and can also sell local products and promote culture [2-5]. Although globalized tourism has brought miscellaneous economic benefits and cultural exchanges, it has brought some negative impacts, including environmental damage, social disorder, and foreign cultural influences. These negative impacts have attracted increasing attention from international environmental groups, especially in the aspect of the protection of natural resources and the preservation of cultural assets $[2,3,6-8]$. As a result, the tourism industry is moving towards sustainable development in search of more sustainable tourism development, planning, and management [3].

In order to achieve sustainable development of the tourism industry, we have to make many efforts to incorporate sustainability awareness into the tourism industry $[7,8]$. Sustainability can be composed of three main aspects: environmental, social, and economic. These aspects must complement each other to form a complete sense of sustainability [4]. Undoubtedly, the awareness of sustainable development has been increasingly integrated into tourism itineraries [5-8]. For example, Gkoumas [9] proposed an assessment framework for sustainable tourism, using qualitative interviews to discuss sustainable development in Mediterranean tourism. Asmelash and Kumar [10] combined Exploratory Factor Analysis (EFA) and Structural Equation Modeling (SEM) to analyze the progress and status of the Tigrai Regional State's tourism sustainability. Hsu et al. [11] developed an attitude assessment scale for sustainable tourism that measures the quality of tourism in the island environment of eastern Taiwan.

In recent years, Sustainable Sports Tourism (SST) has gradually emerged, and it has become a novel industry. [6]. The integration of sports into tourism itineraries has become increasingly popular internationally, with many countries, from large cities to small local towns, establishing specialized sports tourism organizations or events to attract more tourists from other places [1,4]. Yang et al. [4] believe that tourism itineraries combined with sports events can help promote sustainable tourism development, because in addition to increasing economic benefits, it can also allow tourists to stay in the same place for a long time to reduce the amount of traffic diversion to lessen carbon emissions. Musavengane et al. [3] identified riskiness as an important aspect of assessing SST. Traveling in African countries requires not only sustainability, but also increased safety preparations during travel. There rises a research into the integration of sports and sustainable tourism [12-16]. Pouder et al. [1] explored the economic development of sports tourism and its potential market. They identified fellow experts for meetings to determine the best development goals for the sporting events and travel itineraries. Fromel et al. [13] surveyed the people's preference for sports tourism. The study collected 17,032 research samples over a 10-year period. The respondents aged from 12 to 25 were from the Czech Republic and Poland. Their study shows that gender differences can affect sports preferences. Cooper et al. [14] discussed the impact of COVID-19 on sustainable sports tourism, and they acknowledged that sports can play an important role in the economy, society and the environment. Gil-Alana et al. [17] tested whether "fluctuations in financial exchange rates" have a significant impact on the "returns" of sports tourism in Brazil using a multiple linear regression model. Yang et al. [4] combined Bayesian Best Worst Method (Bayesian BWM) and the Visekriterijumska Optimizacija i Kompromisno Resenje (VIKOR) technique to select potential sports tourist attractions in central Taiwan.

The literature reviewed above has made many contributions to both sustainable tourism and sports tourism. However, the existing academic research related to SST still has some shortcomings and limitations, including: 
- Few SST studies have examined the structure of interdependent relationships of the assessed attributes. In fact, these attributes are rarely independent. However, most statistical methods still assume that the factors are independent.

- The use of statistical methods requires some basic assumptions. However, many more post-analytic tests are needed to verify the validity of these assumptions.

- Human perceptions and attitudes are uncertain and subjective. However, few SST studies have considered the factor of information uncertainty.

Therefore, this study proposes a novel Multiple Attribute Decision-making (MADM) assessment framework to explore the development performance of SST. The aims of this study include developing a SST assessment framework and a new hybrid MADM model, identifying the mutual influential relationships among attributes, generating attribute influence weights, and calculating the performance of the evaluated items. The MADM model is an extension of the grey-based approach proposed by Lo et al. [18]. In this study, we use grey theory to reflect the uncertainty of experts in answering questions during interviews. The model can be divided into three stages. First, experts are invited to discuss at a meeting to determine the appropriate assessment attributes for the evaluated items. The Grey Decision-Making Trial and Evaluation Laboratory (GDEMATEL) is used to analyze the mutual influential relationships and feedback among attributes, and a cause-and-effect diagram is generated to help decision-makers understand which attributes are the primary influencing factors and influenced factors. Then, the results of GDEMATEL are used as input to the GDEMATEL-based Analytic Network Process (GDANP) to generate the influence weights of the attributes and their rankings. Finally, the expanded Probability-based Grey Relational Analysis (expanded PGRA) integrates the performance of the evaluated items obtaining the gap with the aspiration level. The expanded PGRA proposed in this study improves the original PGRA technique by introducing the concept of aspiration level into the PGRA calculation process, replacing the traditional concept of "relative satisfaction" with "aspiration level". This approach not only avoids the need to "choose a relatively good apple among rotten apples", but also eliminates the need to limit the number of evaluated items to at least two, that is, one evaluated item can also be analyzed. When implementing expanded PGRA, the worst and aspiration levels are regarded as two evaluated items. The gap between the evaluated item and the aspiration level is the real "room for improvement," so that more improvement information can be acquired in the actual application. This study applies one of the most famous scenic spots in Taiwan, "Sun Moon Lake", as a demonstration case of the proposed model. This paper can provide more reliable improvement implications for the evaluated scenic spot, so that they can move towards SST development more directionally. In addition, the proposed model provides a novel decision-making tool for the decision problem.

The structure of the paper is described below. Section 2 introduces the proposed hybrid model, in which the concepts and computational procedures of GDEMATEL, GDANP, and extended PGRA are introduced in detail. Section 3 applies a real case of Sun Moon Lake as a demonstration of the model to prove the feasibility and practicality of the proposed model, and Section 4 concludes the full discussion and provides the management implications. Section 5 gives the conclusion and future research directions.

\section{The Proposed Hybrid MADM Model}

Most studies discussing SST issues have applied statistical methods such as hypothesis test and regression analysis. However, the independence between the attributes assumed within these SST frameworks does not reflect real-world situations. The model proposed here seeks to overcome the shortcomings of prior methods in three stages. First, the GDEMATEL is used to construct the complex system of relationships among the attributes [18-21]. Second, the GDANP is applied to obtain the influence weights for each attribute. The method uses the analysis results of GDEMATEL as input data for calculations. The interdependency is considered along with the influence weights of the attributes in the modelling $[22,23]$. A cause-and-effect diagram is also derived from the GDEMATEL 
analysis. As noted in Section 1, human perceptions and attitudes are uncertain and subjective. The linguistic variables used in all expert surveys take into account the uncertainty of information. Finally, the "aspiration level" is defined as the maximum performance level for the development of SST in the evaluated items. This paper introduces the concept of aspiration level to improve the conventional PGRA technique. The expanded PGRA can assess the true performance of the evaluated items without defuzzification program. The analysis flowchart of this study is presented in Figure 1. The mentioned methods are also introduced and explained in detail in the following content.

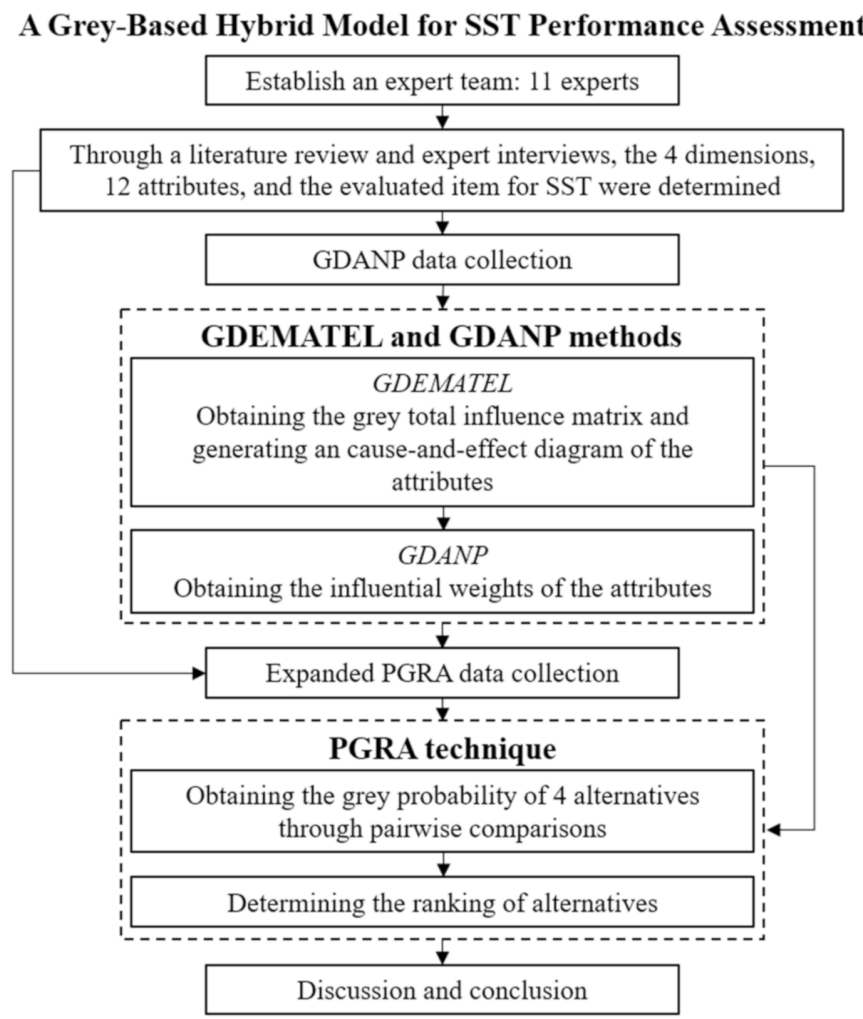

Figure 1. The analysis flowchart of this study.

\subsection{GDEMATEL}

DEMATEL was first proposed by Gabus and Fontela [19] at the Battelle Memorial Institute of Geneva. The technique is to generate a cause-and-effect diagram from a mutual influential relationship matrix for decision-makers to easily understand the interdependent relationship among the attributes. DEMATEL uses five-scale linguistic variables to represent the degree of influence of an attribute. The DEMATEL questionnaire has a different answer concept from the common Analytic Hierarchy Process (AHP). AHP is a method of attribute importance assessment. For example, if the "importance" of attribute $q$ is 3 times that of attribute $p$, then the importance of attribute $p$ is $1 / 3$ times that of attribute $q$, and the importance of $q$ and $p$ is in a reciprocal relationship. DEMATEL assesses the "influence" between attributes $q$ and $p$, and they will not have a reciprocal relationship with each other. Let us take a practical example, electricity and water resources. Water resources need to be supported by some electricity to support transport operations, and electricity can be generated by water resources (e.g., hydroelectricity). In the real world, complex relationships among many factors are common [20,21].

GDEMATEL combines the grey theory with DEMATEL to convert the crisp value into a grey interval, and the detailed calculation process is described as follows.

Step 1: The experts fill in the GDEMATEL questionnaire to obtain the grey direct average relation matrix $\otimes \boldsymbol{R}$. 
The GDEMATEL questionnaire still uses five scales to convert qualitative judgments into quantitative data; the scales include "no influence (N)," "very low influence (VL)," "low influence (L)," "high influence (H)," and "very high influence (VH)," as shown in Table 1.

Table 1. Linguistic variables and the corresponding grey numbers of the Grey Decision-Making Trial and Evaluation Laboratory (GDEMATEL) [18].

\begin{tabular}{ccc}
\hline Linguistic Variables & Codes & Grey Numbers \\
\hline No influence & $\mathrm{N}$ & {$[0,0]$} \\
\hline Very low influence & $\mathrm{VL}$ & {$[0,1]$} \\
\hline Low influence & $\mathrm{L}$ & {$[1,2]$} \\
\hline High influence & $\mathrm{H}$ & {$[2,3]$} \\
\hline Very high influence & $\mathrm{VH}$ & {$[3,4]$} \\
\hline
\end{tabular}

The experts are asked to assess the influence among attributes based on the linguistic variables in Table 1. Assume that the $k$ th expert of the assessment system assesses the influence of attribute $i$ on attribute $j$, which can be denoted as $\otimes r_{i j}^{(k)}, k=1,2, \ldots, K$; $i=j=1,2, \ldots, n$, where the " $\otimes$ " notation represents the grey interval, and the " $\otimes$ " contains the upper and lower bound values, as in $\otimes r_{i j}=\left[r_{i j}^{L}, r_{i j}^{U}\right]$. Averaging all experts' assessment data, the GDEMATEL questionnaire yields the grey direct average relation matrix $\otimes \boldsymbol{R}$, as in Equation (1).

$$
\otimes \boldsymbol{R}=\left[\otimes r_{i j}\right]_{n \times n}=\left[\begin{array}{cccc}
\otimes r_{11} & \otimes r_{12} & \cdots & \otimes r_{1 n} \\
\otimes r_{21} & \otimes r_{22} & \cdots & \otimes r_{2 n} \\
\vdots & \vdots & \ddots & \vdots \\
\otimes r_{n 1} & \otimes r_{n 2} & \cdots & \otimes r_{n n}
\end{array}\right], i=j=1,2, \ldots, n
$$

where $\otimes x_{j j}$ (all diagonal elements) is 0 .

Step 2: Obtaining the grey initial direct influence matrix $\otimes \boldsymbol{A}$.

The calculation procedures in Step 2 and Step 3 split the grey interval, i.e., all lower bound values are executed, then all upper bound values, and finally the values of the grey interval are unified into one set. Through Equations (2) and (3), the grey direct average relation matrix $\otimes \boldsymbol{R}$ can be normalized to obtain the grey initial direct influence matrix $\otimes \boldsymbol{A}$, as in Equation (4).

$$
\otimes A=\otimes \varphi \cdot \otimes \boldsymbol{R}
$$

where

$$
\begin{gathered}
\otimes \varphi=\min \left\{\frac{1}{\max _{i} \sum_{j=1}^{n}\left|\otimes r_{i j}^{U}\right|}, \frac{1}{\max _{j} \sum_{i=1}^{n}\left|\otimes r_{i j}^{U}\right|}\right\} \\
\otimes A=\left[\otimes a_{i j}\right]_{n \times n}=\left[\begin{array}{cccc}
\otimes a_{11} & \otimes a_{12} & \cdots & \otimes a_{1 n} \\
\otimes a_{21} & \otimes a_{22} & \cdots & \otimes a_{2 n} \\
\vdots & \vdots & \ddots & \vdots \\
\otimes a_{n 1} & \otimes a_{n 2} & \cdots & \otimes a_{n n}
\end{array}\right], i=j=1,2, \ldots, n
\end{gathered}
$$

Step 3: Calculating the grey total influence matrix $\otimes \boldsymbol{T}$.

The direct and indirect influence of the assessment system is integrated by the matrices $\otimes \boldsymbol{A}, \otimes \boldsymbol{A}^{2}, \otimes \boldsymbol{A}^{3}, \ldots, \otimes \boldsymbol{A}^{h}$ and $\lim _{h \rightarrow \infty} \otimes \boldsymbol{A}^{h}=[0]_{n \times n^{\prime}}$, where $\otimes \boldsymbol{A}=\left[\otimes a_{i j}\right]_{n \times n^{\prime}} 0 \leq \otimes a_{i j}<1$, $0<\sum_{i=1}^{n} \otimes a_{i j} \leq 1,0<\sum_{j=1}^{n} \otimes a_{i j} \leq 1$ and at least one column sum $\sum_{i} \otimes a_{i j}$ or one row sum $\sum_{j} \otimes a_{i j}$ is set equal to one. According to Equation (5), the grey total influence matrix $\otimes \boldsymbol{T}$ can be calculated, as in Equation (6). 


$$
\begin{gathered}
\otimes \boldsymbol{T}^{h}=\otimes \boldsymbol{A}+\otimes \boldsymbol{A}^{2}+\cdots+\otimes \boldsymbol{A}^{h}=\otimes \boldsymbol{A}(\boldsymbol{I}-\otimes \boldsymbol{A})^{-1}, \text { in which } \\
\lim _{h \rightarrow \infty} \otimes \boldsymbol{A}^{h}=[0]_{n \times n} \\
\otimes \boldsymbol{T}=\left[\otimes t_{i j}\right]_{n \times n}=\left[\begin{array}{cccc}
\otimes t_{11} & \otimes t_{12} & \cdots & \otimes t_{1 n} \\
\otimes t_{21} & \otimes t_{22} & \cdots & \otimes t_{2 n} \\
\vdots & \vdots & \ddots & \vdots \\
\otimes t_{n 1} & \otimes t_{n 2} & \cdots & \otimes t_{n n}
\end{array}\right], i=j=1,2, \ldots, n
\end{gathered}
$$

where $I$ represents the identity matrix, and the symbol "superscript -1 " represents the inverse matrix.

Step 4: Calculating total influence and net influence.

The elements in the grey total influence matrix $\otimes \boldsymbol{T}$ represent the total influence among attributes, and the larger $\otimes t_{i j}$, the stronger the influence. Generally speaking, the total average of the elements in the matrix $\otimes \boldsymbol{T}$ can be used as the threshold for identifying influence. The elements $\otimes t_{i j}$ greater than the threshold indicate relatively strong influence. The rows and columns of the matrix are summed separately, as in Equations (7) and (8).

$$
\begin{gathered}
\otimes \boldsymbol{d}=\left(\otimes d_{1}, \otimes d_{2}, \ldots, \otimes d_{n}\right)=\left(\otimes d_{i}\right)=\left[\sum_{j=1}^{n} \otimes t_{i j}\right]_{n \times 1} \\
\otimes s=\left(\otimes s_{1}, \otimes s_{2}, \ldots, \otimes s_{n}\right)^{T}=\left(\otimes s_{j}\right)^{T}=\left(\otimes s_{i}\right)=\left[\sum_{i=1}^{n} \otimes t_{i j}\right]^{T} 1 \times n
\end{gathered}
$$

where the symbol "superscript $T$ " is a matrix transposition, $\otimes d_{i}$ is the sum of the $i$ th row of the matrix $\otimes \boldsymbol{T}$ into a column, and similarly, $\otimes s_{j}$ is the sum of the $j$ th column of the matrix $\otimes \boldsymbol{T}$ into a row, and $\otimes s_{j}$ is transposed to obtain $\otimes s_{i}$ (row transposition transforming into a column). The total influence and net influence are $\otimes d_{i}+\otimes s_{i}$ and $\otimes d_{i}-\otimes s_{i}$, respectively. To identify the causal relationship of attributes, we use $\otimes d_{i}-\otimes s_{i}$ as a judgment indicator. When $\otimes d_{i}-\otimes s_{i}$ is greater than 0 , the attribute $j$ is a causal attribute (affects others more than it is affected by others). Conversely, when $\otimes d_{i}-\otimes s_{i}$ is less than 0 , then the attribute $j$ is an affected attribute (affects others less than it is affected by others).

Step 5: Drawing the cause-and-effect diagram.

Here, the centroid method is used to defuzzify the fuzzy values (e.g., $\left.\otimes \lambda=\left(\lambda^{L}, \lambda^{U}\right)\right)$ to obtain the crisp value $(\lambda)$, as in Equation (9).

$$
\lambda=0.5\left(\lambda^{L}+\lambda^{U}\right)
$$

$\otimes d_{i}$ and $\otimes s_{i}$ are defuzzified to obtain the explicit values of $d_{i}$ and $s_{i}$. The cause-andeffect diagram has the horizontal axis $d_{i}+s_{i}$ and the vertical axis $d_{i}-s_{i}$. Each attribute is plotted at the corresponding coordinate position according to its $d_{i}$ and $s_{i}$. The element $t_{i j}$ above the threshold value identifies which attribute $i$ influences which attribute $j$, and the arrows are drawn (indicating the direction of influence) to generate a systematic causeand-effect diagram [18].

\subsection{GDANP}

GDANP is based on the grey total influence matrix $\otimes \boldsymbol{T}$ of GDEMATEL to derive a set of valid attribute influence weights that not only reflect the influence of attributes but also take into account the uncertainty of the assessment. GDANP has been widely used in various decision-making problems. For example, quality of service measurement for bike-sharing [22], offshore wind power site selection [18], exploration of factors affecting sustainable intermodal freight transport system [23], and risk factor identification for product lifecycle [24]. The operational process is summarized below.

Step 1: Apply the grey total influence matrix to calculate the normalized matrix. 
Based on the GDEMATEL introduced in Section 2.1, the grey total influence matrix $\otimes \boldsymbol{T}$ can show the interaction of all attributes. As described in Step 2 of GDEMATEL, the lower bound and the upper bound are executed separately when performing the matrix calculation on grey values. If the attributes are classified into several dimensions, the matrix $\otimes \boldsymbol{T}$ can be expressed as the matrix $\otimes \boldsymbol{T}_{C}$, as in Equation (10).

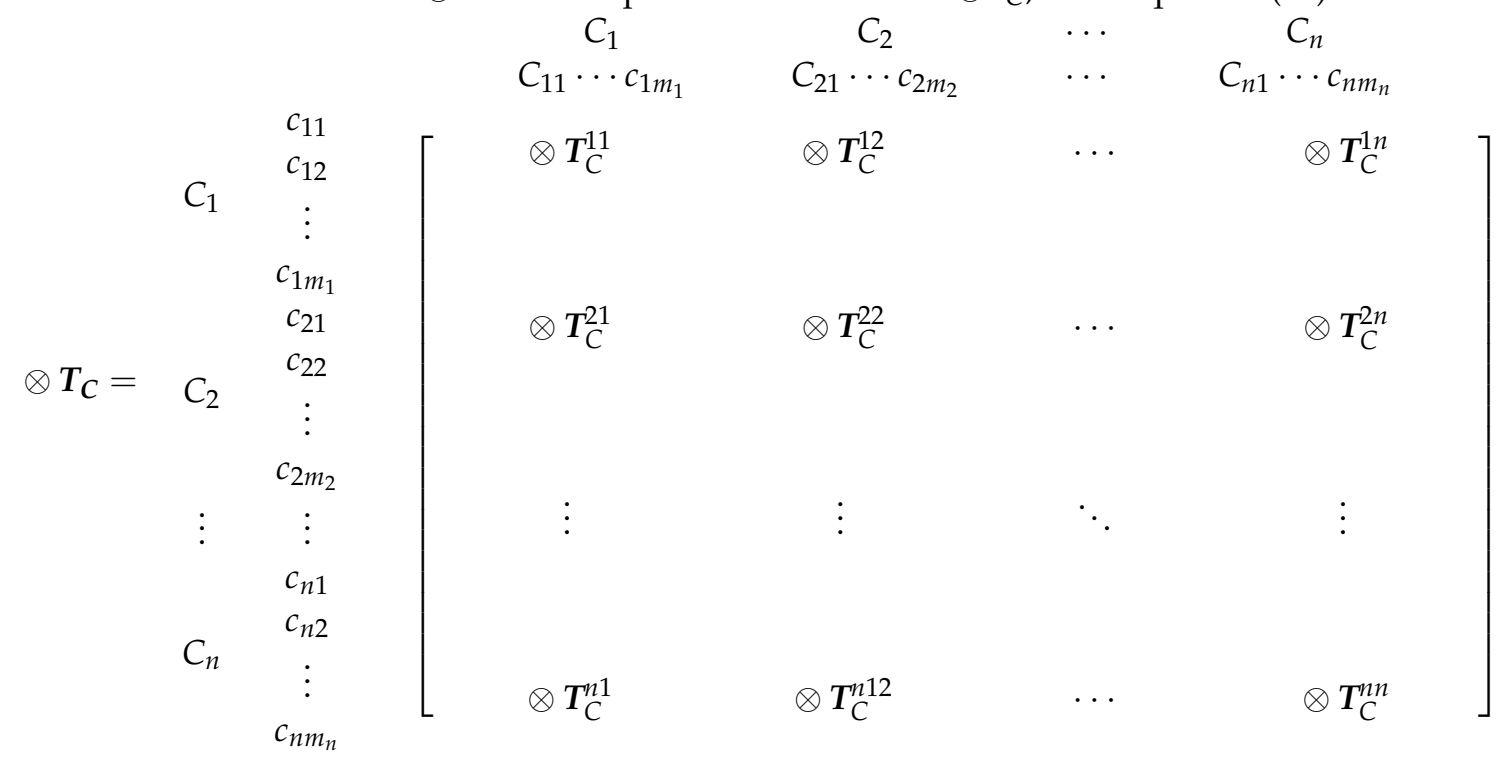

where $C_{n}$ denotes the $n$th dimension and $C_{n m}$ denotes the $m$ th attribute in the $n$th dimension.

According to the ANP algorithm, the un-weighted super-matrix can be formed by summing each row into a column and requiring each column to sum to 1 [18]. For example, the influence matrix of dimension $C_{1}$ on dimension $C_{2}$ in the matrix $\otimes \boldsymbol{T}$ is denoted as $\otimes T_{C}^{12}$, then the matrix $\otimes \boldsymbol{T}_{C}^{12}$ is a sub-matrix of the matrix $\otimes \boldsymbol{T}_{C}$ (Equation (10)), which is obtained by normalizing Equation (12). The normalized matrix of the matrix $\otimes \boldsymbol{T}_{C}$ can be constructed according to this procedure, which is the matrix $\otimes \mathbf{T}_{\mathrm{C}}^{\alpha}$.

$$
\begin{aligned}
& \otimes \boldsymbol{T}_{c}^{12}=\begin{array}{c}
c_{11} \\
\vdots \\
c_{1 i} \\
\vdots \\
c_{1 m_{1}}
\end{array}\left[\begin{array}{ccccc}
\otimes t_{11}^{12} & \cdots & \otimes t_{1 j}^{12} & \cdots & \otimes t_{1 m_{2}}^{12} \\
\vdots & & \vdots & & \vdots \\
\otimes t_{i 1}^{12} & \cdots & \otimes t_{i j}^{12} & \cdots & \otimes t_{i m_{2}}^{12} \\
\vdots & & \vdots & & \vdots \\
\otimes t_{m_{1} 1}^{12} & \cdots & \otimes t_{m_{1}}^{12} & \cdots & \otimes t_{m_{1} m_{2}}^{12}
\end{array}\right] \rightarrow \begin{array}{ccc}
c_{2 m_{2}} \\
\rightarrow & \otimes t_{i}^{12} & =\sum_{j=1}^{m_{2}} \otimes t_{1 j}^{12} \\
\vdots & t_{m_{1}}^{12} & =\sum_{j=1}^{m_{2}} \otimes t_{i j}^{12} \\
m_{m_{1} j}
\end{array} \\
& \text { where } \otimes t_{i}^{12}=\sum_{j=1}^{m_{2}} \otimes t_{i j}^{12}, i=1,2, \ldots, m_{1} \text {, }
\end{aligned}
$$

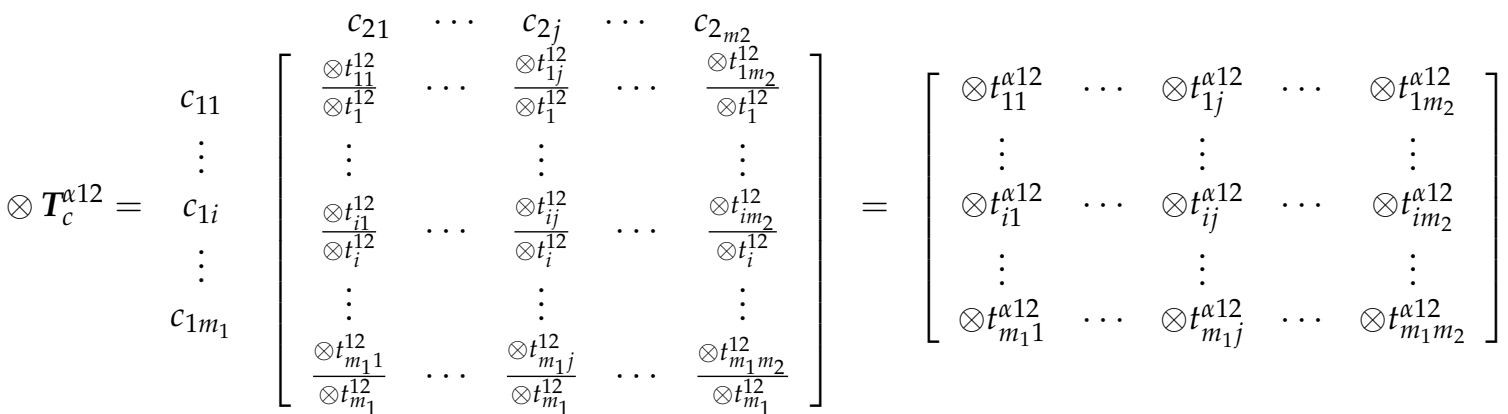

Step 2: Constructing un-weighted super-matrix $\otimes \boldsymbol{W}$.

GDANP continues the concept of ANP. The matrix $\otimes \boldsymbol{T}_{C}^{\alpha}$ must be transposed to obtain the un-weighted super-matrix $\otimes \boldsymbol{W}$, as shown in Equation (13). Continuing the example of Step 1, the sub-matrix of the first row and second column can be denoted as $\left(\otimes \boldsymbol{T}_{C}^{\alpha 12}\right)^{T}=\otimes \boldsymbol{W}_{21}$, as shown in Equation (14). 


$$
\begin{aligned}
& C_{1} \quad C_{2} \quad C_{n} \\
& C_{11} \cdots c_{1 m_{1}} \quad C_{21} \cdots c_{2 m_{2}} \quad \cdots \cdots \quad C_{n 1} \cdots c_{n m_{n}}
\end{aligned}
$$

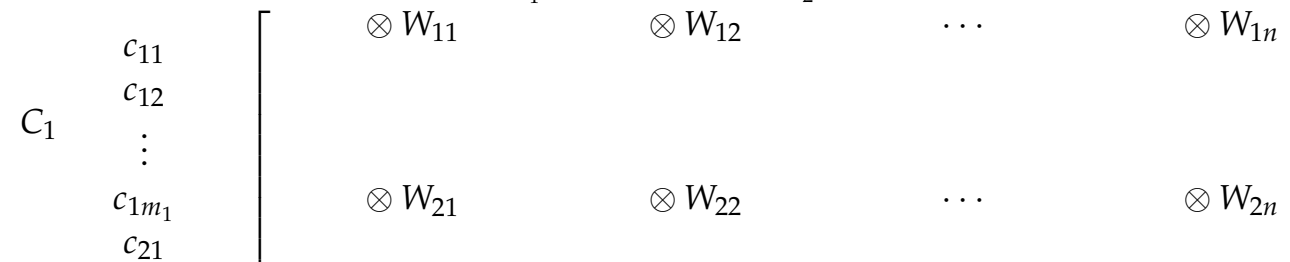

$$
\begin{aligned}
& \otimes W_{21}=\begin{array}{c}
c_{21} \\
\vdots \\
c_{2 j} \\
\vdots \\
c_{2 m_{2}}
\end{array} \quad\left[\begin{array}{ccccc}
\otimes t_{11}^{\alpha_{12}} & \cdots & c_{1 j} & \cdots & c_{1 m_{1}} \\
\vdots & & \vdots & & \vdots \\
\otimes t_{1 j}^{\alpha^{12}} & \cdots & \otimes t_{i j}^{\alpha^{12}} & \cdots & \otimes t_{m_{1} j}^{\alpha^{12}} \\
\vdots & & \vdots & & \vdots \\
\otimes t_{1 m_{2}}^{\alpha^{12}} & \cdots & \otimes t_{i m_{2}}^{\alpha^{12}} & \cdots & \otimes t_{m_{1} m_{2}}^{\alpha^{12}}
\end{array}\right]
\end{aligned}
$$

where $\otimes \boldsymbol{W}_{21}$ is the characteristic vector of the attribute matrix, which is transposed by the $\otimes T_{C}^{\alpha 12}$.

The dependency relation of each attribute has been identified in GDEMATEL. It is not realistic to consider each dimension as equally important. Therefore, Equation (15) is used to generate the normalized grey total influence matrix $\otimes \boldsymbol{T}_{D}^{\alpha}$ for the dimensions, and this derivation is the same as the one used to calculate the matrix $\otimes \mathbf{T}_{C}^{\alpha}$.

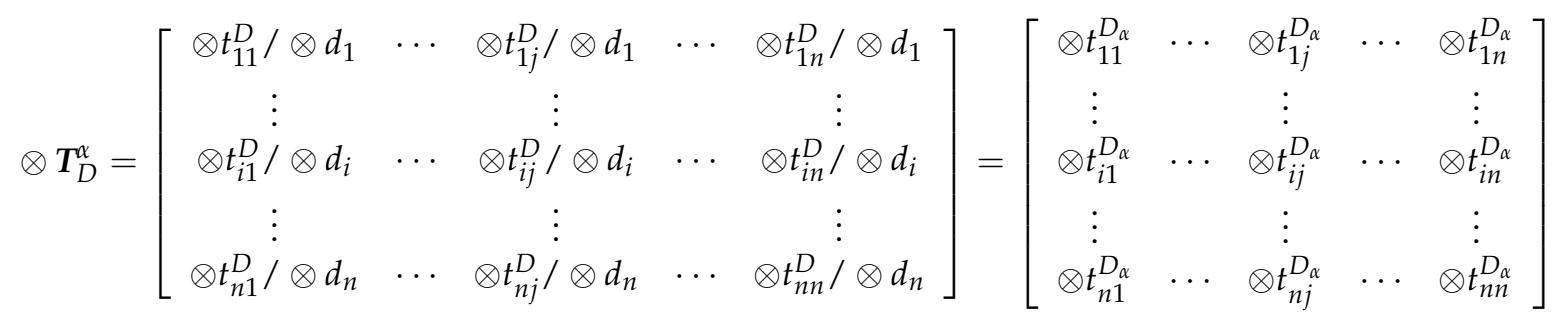

where $\otimes d_{i}=\sum_{j=1}^{n} \otimes t_{i j}^{D}, i=1,2, \ldots, n$.

Next, we multiply $\otimes \boldsymbol{T}_{D}^{\alpha}$ by $\otimes \boldsymbol{W}$ to obtain the weighted super-matrix $\otimes \boldsymbol{W}_{w}$, as shown in Equation (16).

$$
\otimes \boldsymbol{W}_{w}=\otimes \boldsymbol{T}_{D}^{\alpha} \times \otimes \boldsymbol{W}=\left[\begin{array}{ccccc}
\otimes t_{11}^{D_{\alpha}} \times \otimes \boldsymbol{W}_{11} & \otimes t_{21}^{D_{\varepsilon}} \times \otimes \boldsymbol{W}_{12} & \cdots & \cdots & \otimes t_{n 1}^{D_{\alpha}} \times \otimes \boldsymbol{W}_{1 n} \\
\otimes t_{12}^{D_{\alpha}} \times \otimes \boldsymbol{W}_{21} & \otimes t_{22}^{D_{\alpha}} \times \otimes \boldsymbol{W}_{22} & \vdots & & \vdots \\
\vdots & \cdots & \otimes t_{j i}^{D_{\alpha}} \times \otimes \boldsymbol{W}_{i j} & \cdots & \otimes t_{n i}^{D_{\alpha}} \times \otimes \boldsymbol{W}_{i n} \\
\vdots & \vdots & & \vdots \\
\otimes t_{1 n}^{D_{\alpha}} \times \otimes \boldsymbol{W}_{n 1} & \otimes t_{2 n}^{D_{\alpha}} \times \otimes \boldsymbol{W}_{n 2} & \cdots & \cdots & \otimes t_{n n}^{D_{\alpha}} \times \otimes \boldsymbol{W}_{n n}
\end{array}\right]
$$


Step 3: Generating the global influence weights.

The global influence weights are generated by multiplying the weighted super-matrix $\otimes \boldsymbol{W}_{w}$ by itself continuously to achieve matrix stability (each element in the same row has an equal value), as in Equation (17). The values presented in each row represent the influence weights of the attributes. The influence weights of the attributes can be expressed as $\otimes \boldsymbol{w}^{*}, \otimes \boldsymbol{w}^{*}=\left(\otimes w_{1}^{*}, \otimes w_{2}^{*}, \ldots, \otimes w_{n}^{*}\right)$.

$$
\lim _{\rho \rightarrow \infty}\left(\otimes \boldsymbol{W}_{w}\right)^{\rho}
$$

Step 4: Adjusting the proportion to obtain the final influence weights.

The global influence weights $\otimes \boldsymbol{w}^{*}$ can be obtained from the calculation of Equation (17). However, the weights do not reflect the exact proportion of the upper and lower bounds of the grey interval. Therefore, we sum up all the lower and upper bounds of the grey total influence matrix $\otimes \boldsymbol{T}$, as in Equations (18) and (19).

$$
\begin{aligned}
& \alpha=\sum_{i=1}^{n} \sum_{j=1}^{n} t_{i j}^{L} \\
& \beta=\sum_{i=1}^{n} \sum_{j=1}^{n} t_{i j}^{U}
\end{aligned}
$$

Then the final influence weights $\otimes \boldsymbol{w}^{* *}$ can be obtained by Equation (20).

$\otimes \boldsymbol{w}^{* *}=\left(\left[w_{1}^{* L} \cdot \frac{\alpha}{\alpha+\beta}, w_{1}^{* U} \cdot \frac{\beta}{\alpha+\beta}\right],\left[w_{2}^{* L} \cdot \frac{\alpha}{\alpha+\beta}, w_{2}^{* U} \cdot \frac{\beta}{\alpha+\beta}\right], \ldots,\left[w_{n}^{* L} \cdot \frac{\alpha}{\alpha+\beta}, w_{n}^{* U} \cdot \frac{\beta}{\alpha+\beta}\right]\right)$

\subsection{Expanded PGRA}

One of the challenges in expert-assisted decision-making is how to effectively translate expert qualitative judgments into computable quantitative data. Using a linguistic scale of the crisp value type to interpret expert opinion may miss potential information because crisp value does not reflect information uncertainty. Therefore, the use of grey theory is an effective way to deal with uncertainty. PGRA is derived from the notion of interval analysis to embed the GRA technique, which does not require defuzzification to obtain the crisp value like traditional fuzzy methods. PGRA converts a probability by measuring two grey interval values, thus retaining information about the potential assessment experts [25]. Many studies have demonstrated the adaptability of PGRA in uncertain decision-making environments and the results of its analysis can help decision-makers to draw more useful managerial implications. For example, Rajesh and Ravi [25] applied PGRA to select the best supplier for a supply chain. Lo and Liou [26] proposed a novel risk assessment model that combines the Grey Best Worst Method (GBWM) and PGRA to analyze potential failure modes of electronic products. Lo et al. [18] developed an evaluation model for site selection for offshore wind power generation, using PGRA to rank the evaluated projects.

The expanded PGRA proposed in this study improves the original PGRA technique by introducing the concept of aspiration level into the PGRA calculation process, thereby replacing the traditional concept of "relative satisfaction" with "aspiration level". The detailed operation steps of the expanded PGRA are as follows.

Step 1: Experts fill in the PGRA questionnaire to construct the grey initial decision matrix $\otimes$ G.

Expert $k$ is asked to assess the performance of the evaluated item $S_{h}$ under the attribute $C_{j}$ based on the linguistic variables formulated in Table 2, where $k=1,2, \ldots, K$; $j=1,2, \ldots, n$. Here, the aspiration and worst levels are considered as evaluated items. 
Table 2. Linguistic variables and the corresponding grey numbers of the Probability-based Grey Relational Analysis (PGRA) [22].

\begin{tabular}{ccc}
\hline Linguistic Variables & Codes & Grey Numbers \\
\hline Very poor & VP & {$[0,0]$} \\
\hline Poor & P & {$[0,1]$} \\
\hline Medium & M & {$[1,2]$} \\
\hline Good & G & {$[2,3]$} \\
\hline Very good & VG & {$[3,4]$} \\
\hline
\end{tabular}

We obtain the grey initial decision matrix $\otimes \boldsymbol{G}$ by averaging the assessments of all experts, as in Equation (21).

$\otimes \boldsymbol{G}=\left[\otimes g_{h j}\right]_{q \times n}=\left[\begin{array}{cccc}\otimes g_{11} & \otimes g_{12} & \cdots & \otimes g_{1 n} \\ \otimes g_{21} & \otimes g_{22} & \cdots & \otimes g_{2 n} \\ \vdots & \vdots & \ddots & \vdots \\ \otimes g_{q 1} & \otimes g_{q 2} & \cdots & \otimes g_{q n}\end{array}\right], h=1,2, \ldots, q ;=1,2, \ldots, n$

where $\otimes g_{h j}=\left[g_{h j}^{L}, g_{h j}^{U}\right]$.

Step 2: Calculate the grey normalized matrix $\otimes G^{*}$.

The normalization process unifies the assessment units of the attributes. In addition, the elements of the matrix can be made to be between 0 and 1, as in Equation (22). In general, the attributes of properties can be divided into cost and benefit attributes, so the normalization is calculated as Equation (23) and Equation (24), respectively.

$$
\begin{aligned}
& \otimes G^{*}=\left[\otimes g_{h j}^{*}\right]_{q \times n}=\left[\begin{array}{cccc}
\otimes g_{11}^{*} & \otimes g_{12}^{*} & \cdots & \otimes g_{1 n}^{*} \\
\otimes g_{21}^{*} & \otimes g_{22}^{*} & \cdots & \otimes g_{2 n}^{*} \\
\vdots & \vdots & \ddots & \vdots \\
\otimes g_{q 1}^{*} & \otimes g_{q 2}^{*} & \cdots & \otimes g_{q n}^{*}
\end{array}\right], h=1,2, \ldots, q ;=1,2, . ., n \\
& \otimes g_{h j}^{*}=\left[\begin{array}{cc}
\min _{h}^{L} g_{h j}^{L} & \min _{h}^{L} g_{h j}^{U} \\
g_{h j}^{U} & \frac{g_{h j}^{L}}{L}
\end{array}\right], \text { for cos } t \text { attributes } \\
& \otimes g_{h j}^{*}=\left[\frac{g_{h j}^{L}}{\max _{h}^{L},}, \frac{g_{h j}^{U}}{\operatorname{maxg}_{h}^{U}}\right], \text { for benefit attributes }
\end{aligned}
$$

Step 3: Calculating the grey weighted normalized matrix $\otimes \boldsymbol{V}$.

Considering the difference in the influence weights of the attributes, the grey weighted normalized matrix $\otimes \boldsymbol{V}$ (Equation (25)) is obtained by multiplying the grey normalized matrix $\otimes G^{*}$ with the final influence weights $\otimes \boldsymbol{w}^{* *}$ obtained from GDANP as in Equation (26).

$$
\begin{gathered}
\otimes \boldsymbol{V}=\left[\otimes v_{h j}\right]_{q \times n}=\left[\begin{array}{cccc}
\otimes v_{11} & \otimes v_{12} & \cdots & \otimes v_{1 n} \\
\otimes v_{21} & \otimes v_{22} & \cdots & \otimes v_{2 n} \\
\vdots & \vdots & \ddots & \vdots \\
\otimes v_{q 1} & \otimes v_{q 2} & \cdots & \otimes v_{q n}
\end{array}\right], h=1,2, \ldots, q ;=1,2, \ldots, n \\
\otimes V=\left[\left(\otimes g_{h j}^{*}\right) \cdot\left(\otimes w_{j}^{*}\right)\right]_{q \times n}
\end{gathered}
$$

where $\otimes v_{h j}=\left[v_{h j}^{L}, v_{h j}^{U}\right]$. Additionally, the multiplication formula for the grey values is as in Equation (27).

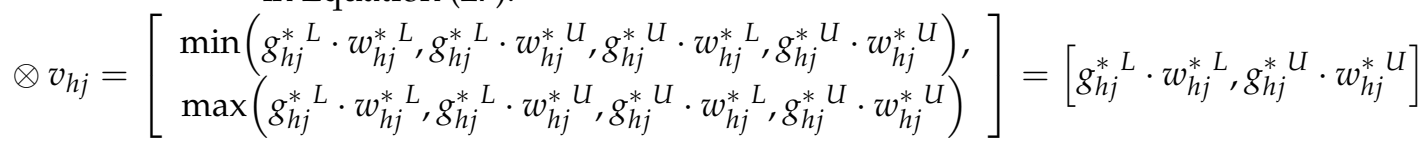


Step 4: Setting the ideal referential solution (IRS) of the evaluated item.

The ideal referential solution of the evaluated item is the aspiration level, as in Equation (28).

$$
S^{\text {aspire }}=\left\{\otimes v_{1}^{\text {aspire }}, \ldots, \otimes v_{j}^{\text {aspire }}, \ldots, \otimes v_{n}^{\text {aspire }}\right\}
$$

where $\otimes v_{j}^{\text {aspire }}=\left[v_{j}^{L \text {,aspire }}, v_{j}^{U \text {,aspire }}\right]$.

Step 5: Obtaining the corresponding grey probability values by comparing the evaluated items with the IRS.

All evaluated items must be paired with the reference ideal solution $S^{\text {asprie }}$ to obtain the grey probability value of each evaluated item. The calculation formula of the concept is as in Equation (29).

$$
Q_{h}=P\left(S_{h} \leq S^{\text {aspire }}\right)=\frac{1}{n} \sum_{j=1}^{n}\left[P\left(\otimes v_{h j} \leq \otimes v_{j}^{\text {aspire }}\right)\right]
$$

The arithmetic logic constructed by interval analysis can convert the two sets of grey numbers into probability, which results in the possibility of being overridden, as in Equations (30) and (31).

$$
\begin{gathered}
Q_{h}=P\left(S_{h} \leq S^{\text {aspire }}\right)=\frac{1}{n} \sum_{j=1}^{n}\left[\frac{\max \left(0, L_{j}^{*}-\max \left(0, v_{h j}^{U}-v_{j}^{L, \text { aspire }}\right)\right)}{L_{j}^{*}}\right] \\
Q_{h}=P\left(S_{h} \leq S^{\text {aspire }}\right)=\frac{1}{n}\left[\begin{array}{c}
\left.+\left[\frac{\frac{\max \left(0, L_{1}^{*}-\max \left(0, v_{h 1}^{U}-v_{1}^{L, \text { aspire }}\right)\right)}{L_{1}^{*}\left(0, L_{2}^{*}-\max \left(0, v_{h 2}^{U}-v_{2}^{L, \text { aspire }}\right)\right)}}{L_{2}^{*}}\right]+\right] \\
\cdots \\
+\left[\frac{\max \left(0, L_{n}^{*}-\max \left(0, v_{h n}^{U}-v_{n}^{L, \text { aspire }}\right)\right)}{L_{n}^{*}}\right]
\end{array}\right]
\end{gathered}
$$

where $L_{j}^{*}$ represents the sum of the lengths of the two grey values of $\otimes v_{h j}$ and $\otimes v_{j}^{\text {aspire }}$, which can be obtained according to Equation (32).

$$
L_{j}^{*}=\left[\left(\otimes v_{h j}^{U}-\otimes v_{h j}^{L}\right)+\left(v_{j}^{U, \max }-v_{j}^{L, \max }\right)\right]
$$

The basic purpose of PGRA is to infer the probability that the reference ideal solution is greater than the evaluated item. When the grey probability value $\mathrm{Qh}$ of the evaluated item is larger, it means that the evaluated item is farther away from the reference ideal solution. The value range of the grey probability value of the evaluated item is between 0.5 and 1. It can be understood from the concept of interval analysis that when the evaluated item is the same as the reference ideal solution, the grey probability value is 0.5 .

Step 6: Calculating the comprehensive performance of the evaluated item.

The grey probability value is a smaller-the-better index, and the value range is between 0 and 0.5 . Therefore, it is necessary to use Equation (33) to convert the grey probability value to a larger-the-better index between 0 and 1 , which is the comprehensive performance.

$$
\theta=\frac{1-Q_{h}}{0.5}
$$

\section{Application of a Real Case: Sun Moon Lake}

\subsection{Case Background and Proposed Assessment Framework}

Sun Moon Lake is one of the most unique sports tourist attractions in central Taiwan, with its most distinctive feature being its vast lake and rich natural ecology. Since 1983, swimming competitions have been held for a distance of about $3000 \mathrm{~m}$. In addition, the 
local scenic area management office actively promotes sports events combined with tourism. Starting from 2018, a series of sports events including "Swimming Across Sun Moon Lake", "Cycling Around the Lake", "Running around the Lake", "Climbing to the Summits of 100 Suburban Mountains" have been held one after another. According to the Sun Moon Lake National Scenic Area, the sports tourism activities held in recent years have attracted many visitors.

At first, this research invited 13 experts to discuss the development of SST in Sun Moon Lake. In the end, 11 experts accepted our invitation to form an expert team, which met several times reviewing many relevant papers to determine the appropriate assessment attributes and framework, which is shown in Figure 1. The experts selected were knowledgeable and reliable, being equipped with more than 10 years of active work experience in their respective fields. The 11 experts included local chief officers, management office directors, well-known local hotel managers, and travel agency operators. These experts have long been involved in the development of SST in Sun Moon Lake and have experience in implementing many sports tourism events.

After careful literature review, the proposed dimensions refer to the research of Yang et al. [4], Gkoumas [9], and Asmelash and Kumar [10]. They are economic sustainability (ES), environmental sustainability (GS), social sustainability (SS), and institutional sustainability (IS). After multiple screenings by the expert team, each dimension is composed of three attributes, for a total of 12 assessment attributes: local employment growth (ES1), local economic feasibility (ES2), sports diversity (ES3), physical integrity (GS1), flora and fauna diversity (GS2), environmental pollution control (GS3), social equity (SS1), tourist safety and emergency rescue (SS2), local social welfare and security (SS3), disease prevention (IS1), policy promotion and marketing (IS2), local government involvement (IS3). Figure 2 shows the SST assessment framework and Table 3 presents descriptions of all attributes and corresponding references.

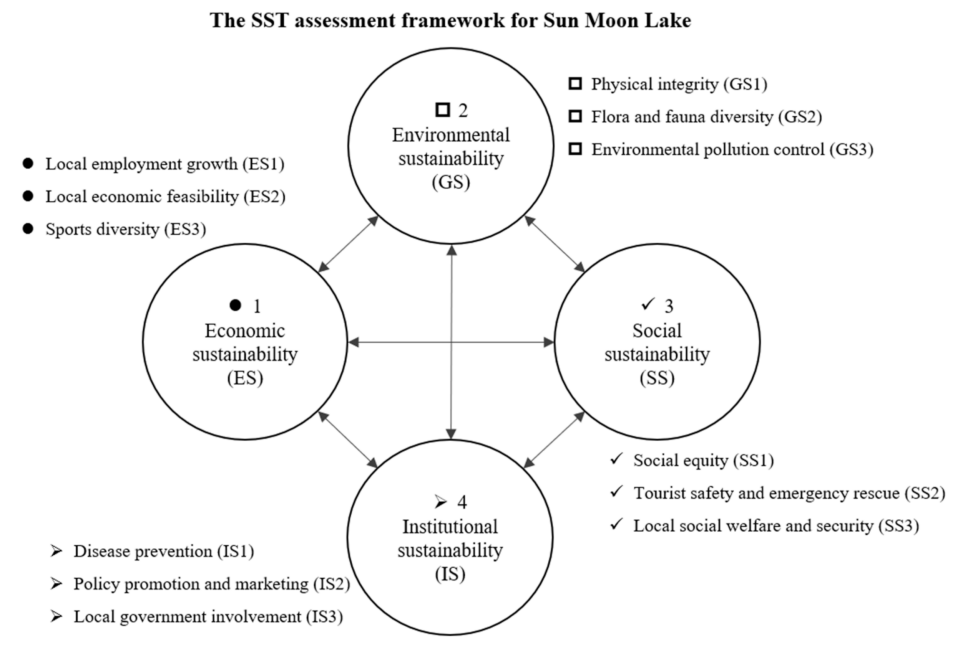

Figure 2. The sustainable sports tourism (SST) assessment framework.

Table 3. Descriptions and references of attributes.

\begin{tabular}{cccc}
\hline Dimension & Attribute & Description & References \\
\hline Economic sustainability (ES) & $\begin{array}{c}\text { Local employment growth } \\
\text { (ES1) }\end{array}$ & $\begin{array}{c}\text { The development of sports tourism in Sun } \\
\text { Moon Lake can bring more employment } \\
\text { opportunities for local residents. }\end{array}$ & $\begin{array}{c}\text { Huang et al. [27]; } \\
\text { Pouder et al. [1]; } \\
\text { Hsu et al. [11] }\end{array}$ \\
\hline Local economic feasibility \\
(ES2) & $\begin{array}{c}\text { Using Sun Moon Lake's local natural resources } \\
\text { to build profitable economic activities can } \\
\text { create higher income with minimal planning } \\
\text { and maintenance costs. }\end{array}$ & $\begin{array}{c}\text { Huang et al. [27]; } \\
\text { Gil-Alana et al. [17]; } \\
\text { Hsu et al. [11] }\end{array}$ & \\
\hline
\end{tabular}


Table 3. Cont.

\begin{tabular}{|c|c|c|c|}
\hline Dimension & Attribute & Description & References \\
\hline & Sports diversity (ES3) & $\begin{array}{l}\text { The diversity of sports in Sun Moon Lake can } \\
\text { attract more visitors of different age groups to } \\
\text { participate in the attractions and promote local } \\
\text { prosperity and economic benefits. }\end{array}$ & $\begin{array}{l}\text { Huang et al. [27]; Yang et al. [4]; } \\
\text { Yang et al. [16] }\end{array}$ \\
\hline \multirow[t]{3}{*}{$\begin{array}{c}\text { Environmental } \\
\text { sustainability (GS) }\end{array}$} & Physical integrity (GS1) & $\begin{array}{l}\text { The current situation of Sun Moon Lake should } \\
\text { be preserved as much as possible without } \\
\text { adding facilities or destroying any buildings and } \\
\text { natural environment. }\end{array}$ & Lee and Jan [2]; Yang et al. [16] \\
\hline & $\begin{array}{l}\text { Flora and fauna diversity } \\
\text { (GS2) }\end{array}$ & $\begin{array}{c}\text { The diversity and richness of the local animals } \\
\text { and plants at Sun Moon Lake should be } \\
\text { preserved. }\end{array}$ & Hsu et al. [11]; Huang et al. [27] \\
\hline & $\begin{array}{l}\text { Environmental pollution } \\
\text { control (GS3) }\end{array}$ & $\begin{array}{l}\text { The environmental pollution of Sun Moon Lake } \\
\text { should be minimized, including exhaust gas } \\
\text { from automobiles and motorcycles, garbage } \\
\text { brought by passengers, and noise from sports } \\
\text { events. }\end{array}$ & $\begin{array}{l}\text { Lee and Jan [2]; } \\
\text { Musavengane et al. [3] }\end{array}$ \\
\hline \multirow[t]{3}{*}{ Social sustainability (SS) } & Social equity (SS1) & $\begin{array}{l}\text { Sun Moon Lake should not be restricted to target } \\
\text { tourists, and services should not be treated } \\
\text { differently due to social status and family } \\
\text { income. In addition, hardware facilities and } \\
\text { buildings should provide a barrier-free passage } \\
\text { for the disabled to maintain social equity. }\end{array}$ & Yang et al. [4]; Pouder et al. [1] \\
\hline & $\begin{array}{l}\text { Tourist safety and } \\
\text { emergency rescue (SS2) }\end{array}$ & $\begin{array}{l}\text { Emergency response and rescue planning to } \\
\text { ensure the safety of sports tourism. }\end{array}$ & Yang et al. [4]; Yang et al. [16] \\
\hline & $\begin{array}{l}\text { Local social welfare and } \\
\text { security (SS3) }\end{array}$ & $\begin{array}{l}\text { The basic rights of residents should be } \\
\text { guaranteed, and their lifestyle should be } \\
\text { maintained as much as possible. Residents } \\
\text { should be given additional living subsidies and } \\
\text { preferential plans for related facilities. }\end{array}$ & Yang et al. [4]; Yang et al. [16] \\
\hline \multirow[t]{3}{*}{$\begin{array}{c}\text { Institutional } \\
\text { sustainability (IS) }\end{array}$} & Disease prevention (IS1) & $\begin{array}{l}\text { Preventive measures for epidemic viruses and } \\
\text { infectious diseases should be drawn up. }\end{array}$ & Drafted by this research \\
\hline & $\begin{array}{l}\text { Policy promotion and } \\
\text { marketing (IS2) }\end{array}$ & $\begin{array}{l}\text { The development speed of sports tourism } \\
\text { depends on policy promotion and marketing. } \\
\text { Seasonal or periodic activities can maintain the } \\
\text { stability of local traffic, to avoid falling into } \\
\text { off-peak seasons of the scenic spots. }\end{array}$ & $\begin{array}{l}\text { Asmelash and Kumar [10]; } \\
\text { Gkoumas [9]; Yang et al. [4]; } \\
\text { Yang et al. [16] }\end{array}$ \\
\hline & $\begin{array}{l}\text { Local government } \\
\text { involvement (IS3) }\end{array}$ & $\begin{array}{l}\text { The local government should regularly hold } \\
\text { sports events and sponsor the resources needed } \\
\text { for the events, which can increase the } \\
\text { willingness of residents and tourists to } \\
\text { participate in sports tourism. }\end{array}$ & $\begin{array}{l}\text { Asmelash and Kumar [10]; } \\
\text { Gkoumas [9]; Yang et al. [4]; } \\
\text { Yang et al. [16] }\end{array}$ \\
\hline
\end{tabular}

\subsection{Determining the Influential Relationship Structure of Attributes Using GDEMATEL}

According to Section 2.1, which describes the GDEMATEL implementation procedure, 11 experts were invited to complete the GDEMATEL questionnaire. Table A1 in Appendix A presents the first expert's responses to the GDEMATEL questionnaire, which was answered using linguistic variables. Next, all assessed linguistic variables were converted into corresponding grey values. Finally, the GDEMTEAL questionnaires of the 11 experts were averaged to obtain the grey direct average relation matrix $\otimes \boldsymbol{R}$, as shown in Table A2 in Appendix A. Table A3 in Appendix A presents the grey total influence matrix $\otimes \mathbf{T}$, and the elements of the matrix are the input data for the calculation of the total influence and net influence.

Table 4 shows the calculation results of GDEMATEL. The total influence and net influence after defuzzification are expressed as $d_{i}+s_{i}$ and $d_{i}-s_{i}$, respectively. The attribute IS2 has the largest total influence of 3.926, and the attribute IS3 has the largest net influence, which has a value of 0.574 . Moreover, the causal attributes are ES2, ES3, GS2, IS2, and IS3, indicating that these attributes significantly affect others. Additionally, ES1, GS1, GS3, SS1, 
SS2, SS3, and IS1 belong to affected attributes, indicating that they are the more affected group of attributes in the assessment system. We use indexes " $d_{i}+s_{i}$ " and " $d_{i}-s_{i}$ " to construct a cause-and-effect diagram, and we can learn the detailed mutual influential relationship of attributes, as shown in Figure 3.

Table 4. The sum of influences given and received on attributes.

\begin{tabular}{ccccccc}
\hline & \multicolumn{1}{c}{$\boldsymbol{d}_{i}$} & $\otimes s_{i}$ & $d_{i}$ & $s_{i}$ & $d_{i}+s_{i}$ & $d_{i}-s_{i}$ \\
\hline ES1 & {$[0.677,2.453]$} & {$[0.814,2.640]$} & 1.565 & 1.727 & 3.292 & -0.162 \\
\hline ES2 & {$[0.941,2.995]$} & {$[0.920,2.920]$} & 1.968 & 1.920 & 3.888 & 0.048 \\
\hline ES3 & {$[0.788,2.709]$} & {$[0.788,2.595]$} & 1.749 & 1.692 & 3.440 & 0.057 \\
\hline GS1 & {$[0.705,2.502]$} & {$[0.747,2.479]$} & 1.604 & 1.613 & 3.217 & -0.009 \\
\hline GS2 & {$[0.575,2.167]$} & {$[0.559,2.046]$} & 1.371 & 1.302 & 2.674 & 0.069 \\
\hline GS3 & {$[0.540,2.031]$} & {$[0.692,2.413]$} & 1.286 & 1.553 & 2.838 & -0.267 \\
\hline SS1 & {$[0.343,1.588]$} & {$[0.399,1.743]$} & 0.966 & 1.071 & 2.037 & -0.106 \\
\hline SS2 & {$[0.483,1.825]$} & {$[0.589,2.189]$} & 1.154 & 1.389 & 2.543 & -0.235 \\
\hline SS3 & {$[0.479,1.889]$} & {$[0.548,2.118]$} & 1.184 & 1.333 & 2.517 & -0.149 \\
\hline IS1 & {$[0.459,1.736]$} & {$[0.465,1.885]$} & 1.098 & 1.175 & 2.273 & -0.078 \\
\hline IS2 & {$[1.023,3.160]$} & {$[0.862,2.806]$} & 2.092 & 1.834 & 3.926 & 0.257 \\
\hline IS3 & {$[1.124,3.360]$} & {$[0.755,2.581]$} & 2.242 & 1.668 & 3.910 & 0.574 \\
\hline
\end{tabular}

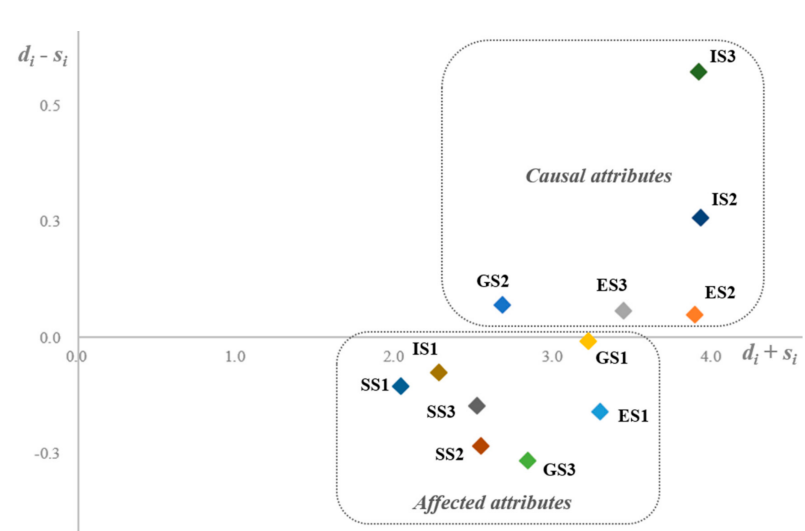

Figure 3. Cause-and-effect diagram of attributes.

\subsection{Generating Impact Weights for Attributes Using GDANP}

As described in Section 2.2, the GDANP method, which combines GDEMATEL and ANP, can be used to obtain the attribute dynamic influential relationships of the assessment system. Using the grey total influence matrix $\otimes \boldsymbol{T}$ obtained from GDEMATEL for derivation, the un-weighted super-matrix $\otimes \boldsymbol{W}$ can be trained, as in Table A4 in Appendix A. GDANP also considers the influential importance of each dimension to avoid using the same dimensional weight to measure attributes. The weighted super-matrix is presented in Table A5 in Appendix A. The GDANP method can obtain the dimensional and attribute weights separately, which helps the decision-makers to understand the importance of each attribute from a holistic perspective, as shown in Table 5. The results show that the top five most important attributes for developing SST at Sun Moon Lake are ES2, IS2, ES1, ES3, and IS3.

\subsection{Applying PGRA to Identify the Performance of SST Development at Sun Moon Lake}

Incorporating the attribute weights derived from GDANP into the analysis of extended PGRA, following the instructions in Section 2.3, the grey probability value of the evaluated item and the gap from the aspiration level can be calculated. First, 11 experts were asked to assess the performance of Sun Moon Lake under 12 attributes. Table A6 in Appendix A 
presents the answers to the PGRA questionnaire of 11 experts. After integration, the grey initial decision matrix $\otimes \boldsymbol{G}$ can be obtained, such as in Table A7 in Appendix A. Next, through a series of interval probability calculation steps in the extended PGRA, the grey probability value of the evaluated item is calculated, as shown in Table 6 . Table 6 presents the grey initial decision matrix of Sun Moon Lake for each attribute, and the closer the value is to 0.5 , the better. Looking at all the attributes, its performance $\theta$ is 0.710 . Furthermore, the gap between Sun Moon Lake and the ideal referential solution is 0.390 . The extended PGRA not only provides a reliable performance index without de-greying, but also allows the gap between the evaluated items and the ideal referential solution to understand how much room for improvement there is. Further discussion and management implications are described in detail in Section 4.

Table 5. GDEMATEL-based Analytic Network Process (GDANP) results.

\begin{tabular}{ccccc}
\hline & $\boldsymbol{\otimes} \boldsymbol{w}_{i}^{*}$ & $\otimes \boldsymbol{w}_{i}^{* *}$ & $\boldsymbol{w}_{\boldsymbol{i}}$ & Rank \\
\hline$E S 1$ & {$[0.098,0.093]$} & {$[0.044,0.144]$} & 0.094 & 3 \\
\hline$E S 2$ & {$[0.114,0.103]$} & {$[0.051,0.160]$} & 0.105 & 1 \\
\hline$E S 3$ & {$[0.097,0.091]$} & {$[0.043,0.142]$} & 0.093 & 4 \\
\hline$G S 1$ & {$[0.092,0.087]$} & {$[0.041,0.135]$} & 0.088 & 6 \\
\hline$G S 2$ & {$[0.069,0.072]$} & {$[0.031,0.112]$} & 0.071 & 10 \\
\hline$G S 3$ & {$[0.085,0.085]$} & {$[0.038,0.132]$} & 0.085 & 7 \\
\hline$S S 1$ & {$[0.049,0.061]$} & {$[0.022,0.095]$} & 0.058 & 8 \\
\hline$S S 2$ & {$[0.071,0.077]$} & {$[0.032,0.119]$} & 0.075 & 9 \\
\hline$S S 3$ & {$[0.067,0.074]$} & {$[0.030,0.116]$} & 0.073 & 11 \\
\hline$I S 1$ & {$[0.058,0.067]$} & {$[0.026,0.103]$} & 0.065 & 2 \\
\hline$I S 2$ & {$[0.107,0.099]$} & {$[0.048,0.154]$} & 0.101 & 5 \\
\hline$I S 3$ & {$[0.095,0.091]$} & {$[0.042,0.142]$} & 0.092 & \\
\hline
\end{tabular}

Table 6. The extended PGRA results.

\begin{tabular}{|c|c|c|c|c|c|c|c|c|c|c|c|c|}
\hline & ES1 & ES2 & ES3 & GS1 & GS2 & GS3 & SS1 & $S S 2$ & SS3 & IS1 & IS2 & IS3 \\
\hline$P\left(\otimes v_{j} \leq \otimes v_{j}^{a s p i r e}\right)$ & 0.644 & 0.597 & 0.683 & 0.583 & 0.569 & 0.604 & 0.674 & 0.672 & 0.696 & 0.780 & 0.645 & 0.594 \\
\hline Performance rank & 6 & 4 & 10 & 2 & 1 & 5 & 9 & 8 & 11 & 12 & 7 & 3 \\
\hline \multicolumn{13}{|c|}{ Overall } \\
\hline$Q_{h}$ & 0.645 & & & & & & & & & & & \\
\hline$\theta$ & 0.710 & & & & & & & & & & & \\
\hline $\operatorname{Gap}(1-\theta)$ & 0.390 & & & & & & & & & & & \\
\hline
\end{tabular}

\section{Discussion and Management Implications}

The development of SST in a region requires significant development time and investment costs. Drawing up an effective and stable assessment system is an important challenge for current sports tourism. GRA is effective in dealing with decision-making problems of complex and mutually constraining attributes. However, although GRA takes into account the uncertainty of the assessment environment and expert judgment, the method still converts interval values to crisp values for computation, which leaves out some information. For example, if interval $\mathrm{A}$ is $[0,10]$ and interval $\mathrm{B}$ is $[4,6]$, after greying out $A$ and $B$ the crisp values of both $A$ and $B$ will be 5 . However, in fact, the ranges implied by A and B are different. At the earliest, Rajesh and Ravi [25] proposed PGRA to overcome the abovementioned problems. Lo and Liou [26] and Lo et al. [18] applied PGRA to discuss the risk assessment of electronic products and the site selection of offshore wind power generation. This study expands the PGRA approach by introducing the concept of aspiration level to optimize the utility of conventional PGRA in real-world cases and 
by adding a reliable performance index to assist decision-makers in judging the results of the analysis more easily. Table 7 summarizes the differences between GRA, PGRA, and Expanded PGRA. Obviously, Expanded PGRA can obtain the gap between the evaluated item and the aspiration level, and can clearly identify room for improvement. In addition, the Expanded PGRA can handle a single evaluated item, unlike the regular PGRA, which requires at least two alternatives.

Table 7. Comparison of differences between GRA, PGRA, and Expanded PGRA.

\begin{tabular}{|c|c|c|c|c|c|}
\hline & Data Type & $\begin{array}{c}\text { Consider Information } \\
\text { Uncertainty }\end{array}$ & Need Defuzzication & $\begin{array}{l}\text { Obtain the Gap with } \\
\text { the Aspiration Level }\end{array}$ & $\begin{array}{l}\text { Able to Assess Just } \\
\text { One Evaluated Item }\end{array}$ \\
\hline Expanded PGRA & Grey interval & Yes & No & Yes & Yes \\
\hline PGRA & Grey interval & Yes & No & No & No \\
\hline GRA & Crisp & Yes & Yes & No & No \\
\hline
\end{tabular}

The GDEMATEL-generated cause-and-effect diagram identifies "IS3", "IS2", "GS2," "ES3," and "ES2" significantly influence the other attributes. In other words, optimizing the performance of these causal attributes can lead to an overall improvement in SST development. The most influential attributes are definitely "IS3" and "IS2," a result that echoes Kapera's [28] study. He points out that local governments are the most appropriate leaders in developing tourism, and their main task is to improve the living standards of local residents and manage local resources. Paunović and Jovanović [29] argue that tourism policy is the result of a compromise among ideas, values, and interests. The strategies, actions, or products adopted by governments impact the development of sustainable tourism.

Moreover, the GDANP method trains a reliable set of attribute influence weights, with larger weights significantly reflecting the success or failure of SST. "ES2,," "IS2," and "ES1" are the top three with the highest weights in the overall assessment system. These three attributes are the most relevant to local economic income. Tourism can be a tool for improving the livelihoods of local communities, with the most perceived source of income being the economic benefits from tourism projects and the sale of souvenirs and related local products [30]. On the other hand, "ES3" and "IS3" are the fourth and fifth ranked attributes, both of which should be valued. The diversity of sports and business models can attract more sports-loving tourists [31]. In particular, local governments, as organizers of major sporting events, can better coordinate the allocation of resources and management among different organizations.

Compared to simple tourism development, SST is less environmentally damaging because it is a combination of sporting events and tourism itineraries that are economically, socially, environmentally, and institutionally focused. Sports tourism mostly takes place as sports events, rather than as part of itineraries like hitting the high spots, which require constant transportation. As the need for transportation is reduced, $\mathrm{CO}_{2}$ emissions are also reduced [4]. Taiwan's Sun Moon Lake National Scenic Area is one of the most famous tourist destinations in Southeast Asia, attracting a large number of domestic and foreign tourists every year, and is very suitable for the development of SST. According to the results of the expended PRGA analysis, Sun Moon Lake currently performs well in the five attribute areas: "GS2", "GS1", "IS3", "ES2", and "GS3". However, in terms of overall performance, there is still room for improvement of 0.390 from the aspiration level. This study suggests that the three attributes of "IS1", "SS3", and "ES3" should be strengthened. Many experts believe that Sun Moon Lake is an open area and the measures for disease prevention and control still need to be improved. For example, intersection control should be set up to ensure the temperature and health status of visitors. In addition to epidemic prevention, more measures and behaviors should be developed to deal with tourism diseases. In addition, the welfare and quality of life of local residents should be improved. It is suggested that subsidies be provided to residents to rebuild the fences around their homes to avoid disturbances caused by the influx of tourists. Finally, the local government 
can plan and create more sports events with special characteristics that can attract tourists to come again and again.

\section{Conclusions}

The proposed hybrid MADM model can be applied to various performance assessment problems. The methodology does not require the prior formulation of assumptions for the execution of the calculation process as in the case of statistical methods. In addition, we take into account the uncertainty of the assessment environment and expert judgment. Overall, this study provides a novel assessment system for SST that can assist decisionmakers and practitioners in making appropriate management strategies. From an academic perspective, we optimized the conventional PGRA approach of Rajesh and Ravi [25], Lo and Liou [26], and Lo et al. [18]. The proposed expanded PGRA overcomes the shortcomings of conventional PGRA, including the ability to effectively identify the gap between the evaluated items and the aspiration level, and the ability to use it for single-item assessment. More accurate room for improvement evaluation can be obtained from expanded PGRA, and it follows the development trend of Multiple Criteria Decision-Making (MCDM) [32]. In addition, the results of the GDEMATEL and GDANP analyses echo the findings of lots of the SST literature.

Although this study has contributed to the issue of SST development, there are still some limitations that need to be addressed. At present, we have only been able to interview 11 experts who are relevant to the development of tourism in Sun Moon Lake, and we hope to find more potential experts to interview in the future. In addition, the way to integrate the expert survey data is by averaging method, and future work can include the Rough Set Theory (RST) to integrate the judgment of multiple experts.

Author Contributions: Conceptualization, C.-C.Y. and H.-W.L.; methodology, H.-W.L.; investigation, C.-C.S. and Y.-S.L.; data curation, C.-C.S. and Y.-S.L.; writing-original draft preparation, C.-C.Y., C.-C.S. and Y.-S.L.; writing-review and editing, H.-W.L.; project administration, J.-Z.W. All authors have read and agreed to the published version of the manuscript.

Funding: This research received no external funding.

Institutional Review Board Statement: Not applicable.

Informed Consent Statement: Not applicable.

Data Availability Statement: Not applicable.

Conflicts of Interest: The authors declare no conflict of interest.

\section{Appendix A}

Table A1. GDEMATEL questionnaire: take the expert 1 as an example.

\begin{tabular}{ccccccccccccc}
\hline & ES1 & ES2 & ES3 & GS1 & GS2 & GS3 & SS1 & SS2 & SS3 & IS1 & IS2 & IS3 \\
\hline ES1 & 0 & VH & L & L & L & H & L & VL & L & VL & L & H \\
\hline ES2 & H & 0 & VL & VL & VL & L & L & L & L & VL & VH & H \\
\hline ES3 & L & L & 0 & H & VL & VL & VL & L & VL & VL & H & H \\
\hline GS1 & L & L & VL & 0 & H & L & L & H & L & L & VL & VL \\
\hline GS2 & N & VL & N & L & 0 & VL & N & N & VL & VL & L & L \\
\hline GS3 & VL & VL & VL & VL & VL & 0 & L & H & VL & H & L & VL \\
\hline SS1 & VL & VL & N & VL & N & VL & 0 & VL & VL & VL & L & L \\
\hline SS2 & VL & L & N & N & N & VL & L & 0 & L & VL & L & L \\
\hline SS3 & H & L & VL & VL & VL & L & H & L & 0 & L & VL & VL \\
\hline IS1 & VL & VL & N & N & VL & H & L & L & L & 0 & VL & VL \\
\hline IS2 & H & H & L & L & VL & VL & N & VL & L & N & 0 & L \\
\hline IS3 & H & H & H & H & L & H & H & L & H & H & H & 0 \\
\hline
\end{tabular}


Table A2. The grey direct average relation matrix $\otimes \boldsymbol{R}$.

\begin{tabular}{|c|c|c|c|c|c|c|c|c|c|c|c|c|}
\hline & ES1 & ES2 & ES3 & GS1 & GS2 & GS3 & SS1 & SS2 & SS3 & IS1 & IS2 & IS3 \\
\hline ES1 & 0 & {$[1.818,2.818]$} & {$[1.364,2.364]$} & {$[1.000,2.000]$} & {$[0.636,1.455]$} & {$[1.273,2.273]$} & {$[0.909,1.727]$} & {$[0.818,1.727]$} & {$[1.364,2.273]$} & {$[0.636,1.545]$} & {$[1.545,2.545]$} & {$[1.273,2.273]$} \\
\hline ES2 & {$[2.091,3.091]$} & 0 & {$[1.909,2.909]$} & {$[1.636,2.636]$} & {$[1.455,2.455]$} & {$[1.273,2.273]$} & {$[0.818,1.727]$} & {$[1.545,2.545]$} & {$[1.364,2.364]$} & {$[1.091,1.818]$} & {$[2.545,3.545]$} & {$[2.000,3.000]$} \\
\hline ES3 & {$[2.091,3.091]$} & {$[2.091,3.091]$} & 0 & {$[2.091,3.091]$} & {$[0.727,1.636]$} & {$[0.727,1.727]$} & {$[0.364,1.273]$} & {$[1.727,2.727]$} & {$[0.364,1.364]$} & {$[0.636,1.545]$} & {$[1.909,2.909]$} & {$[1.727,2.727]$} \\
\hline GS1 & {$[1.000,1.909]$} & {$[1.818,2.818]$} & {$[1.545,2.545]$} & 0 & {$[1.909,2.909]$} & {$[2.000,3.000]$} & {$[0.545,1.455]$} & {$[0.636,1.455]$} & {$[0.909,1.818]$} & {$[0.545,1.273]$} & {$[1.364,2.364]$} & {$[1.000,2.000]$} \\
\hline GS2 & {$[0.818,1.545]$} & {$[1.636,2.636]$} & {$[0.545,1.455]$} & {$[1.545,2.545]$} & 0 & {$[1.727,2.636]$} & {$[0.000,0.545]$} & {$[0.636,1.364]$} & {$[0.636,1.455]$} & {$[0.273,1.091]$} & {$[1.455,2.455]$} & {$[1.182,2.091]$} \\
\hline GS3 & {$[0.545,1.273]$} & {$[1.273,2.273]$} & {$[0.727,1.545]$} & {$[1.182,1.909]$} & {$[1.909,2.909]$} & 0 & {$[0.364,1.091]$} & {$[0.545,1.273]$} & {$[0.727,1.545]$} & {$[1.091,1.909]$} & {$[0.909,1.727]$} & {$[0.909,1.636]$} \\
\hline SS1 & {$[0.818,1.727]$} & {$[1.000,1.818]$} & {$[0.909,1.636]$} & {$[0.364,1.091]$} & {$[0.000,0.455]$} & {$[0.000,0.545]$} & 0 & {$[0.182,0.909]$} & {$[0.909,1.727]$} & {$[0.091,0.727]$} & {$[0.909,1.818]$} & {$[0.909,1.818]$} \\
\hline SS2 & {$[0.545,1.364]$} & {$[1.000,1.727]$} & {$[1.818,2.727]$} & {$[0.727,1.273]$} & {$[0.000,0.273]$} & {$[0.636,1.364]$} & {$[0.273,1.000]$} & 0 & {$[0.273,0.909]$} & {$[1.091,2.000]$} & {$[1.182,2.000]$} & {$[1.182,2.000]$} \\
\hline SS3 & {$[1.273,2.091]$} & {$[1.000,1.909]$} & {$[0.455,1.182]$} & {$[1.000,1.727]$} & {$[0.727,1.273]$} & {$[0.909,1.727]$} & {$[1.091,2.000]$} & {$[0.182,0.818]$} & 0 & {$[0.818,1.545]$} & {$[0.818,1.727]$} & {$[0.818,1.727]$} \\
\hline IS1 & {$[0.818,1.545]$} & {$[0.818,1.727]$} & {$[0.636,1.091]$} & {$[0.273,0.727]$} & {$[0.364,0.818]$} & {$[1.091,1.727]$} & {$[0.273,0.818]$} & {$[1.818,2.727]$} & {$[0.909,1.545]$} & 0 & {$[0.909,1.818]$} & {$[0.818,1.727]$} \\
\hline IS2 & {$[2.636,3.636]$} & {$[2.455,3.455]$} & {$[2.364,3.364]$} & {$[2.000,3.000]$} & {$[1.000,2.000]$} & {$[1.636,2.636]$} & {$[1.182,2.000]$} & {$[1.273,2.273]$} & {$[1.364,2.364]$} & {$[1.091,1.909]$} & 0 & {$[2.364,3.364]$} \\
\hline IS3 & {$[2.545,3.455]$} & {$[2.545,3.545]$} & {$[2.455,3.455]$} & {$[2.091,3.091]$} & {$[1.545,2.545]$} & {$[1.727,2.727]$} & {$[1.545,2.455]$} & {$[1.636,2.636]$} & {$[1.455,2.455]$} & {$[1.273,2.182]$} & {$[2.727,3.727]$} & 0 \\
\hline
\end{tabular}

Table A3. The grey total influence matrix $\otimes \boldsymbol{T}$.

\begin{tabular}{|c|c|c|c|c|c|c|c|c|c|c|c|c|}
\hline & ES1 & ES2 & ES3 & GS1 & GS2 & GS3 & SS1 & SS2 & SS3 & IS1 & IS2 & IS3 \\
\hline ES1 & {$[0.031,0.167]$} & {$[0.087,0.263]$} & {$[0.070,0.231]$} & {$[0.058,0.215]$} & {$[0.040,0.172]$} & {$[0.063,0.217]$} & {$[0.042,0.161]$} & {$[0.046,0.188]$} & {$[0.061,0.199]$} & {$[0.036,0.164]$} & {$[0.077,0.249]$} & {$[0.066,0.228]$} \\
\hline ES2 & {$[0.104,0.291]$} & {$[0.047,0.224]$} & {$[0.097,0.283]$} & {$[0.087,0.267]$} & {$[0.071,0.228]$} & {$[0.073,0.251]$} & {$[0.045,0.184]$} & {$[0.076,0.241]$} & {$[0.068,0.230]$} & {$[0.056,0.197]$} & {$[0.118,0.315]$} & {$[0.097,0.283]$} \\
\hline ES3 & {$[0.097,0.272]$} & {$[0.102,0.291]$} & {$[0.036,0.183]$} & {$[0.094,0.261]$} & {$[0.047,0.191]$} & {$[0.053,0.219]$} & {$[0.029,0.159]$} & {$[0.077,0.231]$} & {$[0.035,0.188]$} & {$[0.040,0.177]$} & {$[0.094,0.279]$} & {$[0.084,0.258]$} \\
\hline GS1 & {$[0.061,0.225]$} & {$[0.088,0.268]$} & {$[0.075,0.239]$} & {$[0.030,0.160]$} & {$[0.079,0.217]$} & {$[0.086,0.241]$} & {$[0.031,0.154]$} & {$[0.041,0.182]$} & {$[0.048,0.188]$} & {$[0.034,0.158]$} & {$[0.073,0.248]$} & {$[0.059,0.223]$} \\
\hline GS2 & {$[0.050,0.193]$} & {$[0.077,0.238]$} & {$[0.042,0.188]$} & {$[0.070,0.213]$} & {$[0.020,0.118]$} & {$[0.074,0.212]$} & {$[0.013,0.114]$} & {$[0.037,0.162]$} & {$[0.037,0.161]$} & {$[0.024,0.138]$} & {$[0.070,0.227]$} & {$[0.059,0.204]$} \\
\hline GS3 & {$[0.040,0.174]$} & {$[0.064,0.217]$} & {$[0.044,0.179]$} & {$[0.057,0.185]$} & {$[0.074,0.191]$} & {$[0.021,0.126]$} & {$[0.022,0.122]$} & {$[0.034,0.151]$} & {$[0.038,0.155]$} & {$[0.046,0.153]$} & {$[0.052,0.196]$} & {$[0.049,0.182]$} \\
\hline SS1 & {$[0.042,0.160]$} & {$[0.048,0.172]$} & {$[0.043,0.155]$} & {$[0.026,0.135]$} & {$[0.011,0.098]$} & {$[0.013,0.115]$} & {$[0.009,0.073]$} & {$[0.017,0.117]$} & {$[0.038,0.138]$} & {$[0.012,0.099]$} & {$[0.044,0.168]$} & {$[0.042,0.159]$} \\
\hline SS2 & {$[0.040,0.166]$} & {$[0.055,0.187]$} & {$[0.076,0.201]$} & {$[0.042,0.154]$} & {$[0.015,0.105]$} & {$[0.037,0.152]$} & {$[0.019,0.112]$} & {$[0.017,0.105]$} & {$[0.023,0.126]$} & {$[0.045,0.147]$} & {$[0.059,0.190]$} & {$[0.056,0.179]$} \\
\hline SS3 & {$[0.058,0.188]$} & {$[0.053,0.196]$} & {$[0.034,0.160]$} & {$[0.048,0.170]$} & {$[0.037,0.137]$} & {$[0.045,0.167]$} & {$[0.043,0.143]$} & {$[0.020,0.130]$} & {$[0.015,0.103]$} & {$[0.036,0.136]$} & {$[0.046,0.186]$} & {$[0.043,0.175]$} \\
\hline IS1 & {$[0.044,0.162]$} & {$[0.046,0.179]$} & {$[0.039,0.149]$} & {$[0.026,0.132]$} & {$[0.024,0.114]$} & {$[0.049,0.157]$} & {$[0.018,0.102]$} & {$[0.069,0.176]$} & {$[0.040,0.139]$} & {$[0.012,0.085]$} & {$[0.048,0.177]$} & {$[0.043,0.165]$} \\
\hline IS2 & {$[0.123,0.317]$} & {$[0.123,0.334]$} & {$[0.113,0.306]$} & {$[0.101,0.287]$} & {$[0.062,0.225]$} & {$[0.086,0.271]$} & {$[0.058,0.200]$} & {$[0.071,0.243]$} & {$[0.071,0.239]$} & {$[0.058,0.208]$} & {$[0.049,0.228]$} & {$[0.111,0.303]$} \\
\hline IS3 & {$[0.124,0.325]$} & {$[0.130,0.351]$} & {$[0.120,0.321]$} & {$[0.107,0.302]$} & {$[0.079,0.249]$} & {$[0.092,0.285]$} & {$[0.070,0.220]$} & {$[0.084,0.263]$} & {$[0.076,0.252]$} & {$[0.065,0.224]$} & {$[0.131,0.345]$} & {$[0.046,0.222]$} \\
\hline
\end{tabular}


Table A4. The un-weighted super-matrix $\otimes W$.

\begin{tabular}{|c|c|c|c|c|c|c|c|c|c|c|c|c|}
\hline & ES1 & ES2 & ES3 & GS1 & GS2 & GS3 & SS1 & SS2 & SS3 & IS1 & IS2 & IS3 \\
\hline ES1 & {$[0.164,0.252]$} & {$[0.418,0.365]$} & {$[0.414,0.365]$} & {$[0.271,0.307]$} & {$[0.297,0.311]$} & {$[0.269,0.306]$} & {$[0.316,0.329]$} & {$[0.233,0.299]$} & {$[0.402,0.345]$} & {$[0.340,0.331]$} & {$[0.342,0.331]$} & {$[0.332,0.326]$} \\
\hline ES2 & {$[0.464,0.398]$} & {$[0.191,0.281]$} & {$[0.431,0.390]$} & {$[0.395,0.366]$} & {$[0.456,0.385]$} & {$[0.434,0.380]$} & {$[0.360,0.353]$} & {$[0.321,0.338]$} & {$[0.366,0.360]$} & {$[0.358,0.365]$} & {$[0.342,0.349]$} & {$[0.347,0.352]$} \\
\hline ES3 & {$[0.372,0.350]$} & {$[0.391,0.354]$} & {$[0.154,0.245]$} & {$[0.334,0.327]$} & {$[0.248,0.304]$} & {$[0.297,0.314]$} & {$[0.324,0.318]$} & {$[0.445,0.363]$} & {$[0.232,0.294]$} & {$[0.302,0.304]$} & {$[0.316,0.320]$} & {$[0.320,0.322]$} \\
\hline GS1 & {$[0.360,0.355]$} & {$[0.376,0.358]$} & {$[0.487,0.389]$} & {$[0.152,0.259]$} & {$[0.427,0.392]$} & {$[0.376,0.368]$} & {$[0.524,0.388]$} & {$[0.448,0.375]$} & {$[0.373,0.358]$} & {$[0.266,0.327]$} & {$[0.405,0.367]$} & {$[0.384,0.361]$} \\
\hline GS2 & {$[0.250,0.286]$} & {$[0.308,0.305]$} & {$[0.241,0.285]$} & {$[0.408,0.351]$} & {$[0.122,0.217]$} & {$[0.485,0.381]$} & {$[0.214,0.281]$} & {$[0.160,0.255]$} & {$[0.282,0.290]$} & {$[0.243,0.284]$} & {$[0.248,0.287]$} & {$[0.285,0.298]$} \\
\hline GS3 & {$[0.390,0.359]$} & {$[0.316,0.337]$} & {$[0.272,0.327]$} & {$[0.441,0.390]$} & {$[0.451,0.391]$} & {$[0.139,0.251]$} & {$[0.262,0.331]$} & {$[0.391,0.370]$} & {$[0.346,0.352]$} & {$[0.491,0.389]$} & {$[0.347,0.346]$} & {$[0.331,0.341]$} \\
\hline SS1 & {$[0.285,0.294]$} & {$[0.239,0.281]$} & {$[0.204,0.276]$} & {$[0.258,0.293]$} & {$[0.150,0.261]$} & {$[0.235,0.284]$} & {$[0.135,0.222]$} & {$[0.323,0.326]$} & {$[0.554,0.381]$} & {$[0.143,0.245]$} & {$[0.290,0.293]$} & {$[0.304,0.299]$} \\
\hline SS3 & {$[0.407,0.363]$} & {$[0.360,0.351]$} & {$[0.250,0.325]$} & {$[0.397,0.359]$} & {$[0.421,0.368]$} & {$[0.403,0.362]$} & {$[0.598,0.421]$} & {$[0.383,0.368]$} & {$[0.186,0.274]$} & {$[0.316,0.332]$} & {$[0.355,0.351]$} & {$[0.331,0.343]$} \\
\hline IS1 & {$[0.203,0.256]$} & {$[0.207,0.248]$} & {$[0.182,0.248]$} & {$[0.205,0.251]$} & {$[0.155,0.242]$} & {$[0.311,0.288]$} & {$[0.120,0.232]$} & {$[0.284,0.285]$} & {$[0.287,0.274]$} & {$[0.118,0.199]$} & {$[0.267,0.281]$} & {$[0.269,0.283]$} \\
\hline IS2 & {$[0.431,0.389]$} & {$[0.434,0.396]$} & {$[0.432,0.391]$} & {$[0.441,0.394]$} & {$[0.459,0.399]$} & {$[0.356,0.370]$} & {$[0.451,0.395]$} & {$[0.367,0.368]$} & {$[0.368,0.374]$} & {$[0.464,0.415]$} & {$[0.224,0.308]$} & {$[0.540,0.436]$} \\
\hline IS3 & {$[0.366,0.355]$} & {$[0.359,0.356]$} & {$[0.386,0.362]$} & {$[0.354,0.355]$} & {$[0.386,0.359]$} & {$[0.333,0.342]$} & {$[0.429,0.373]$} & {$[0.349,0.347]$} & {$[0.346,0.352]$} & {$[0.417,0.386]$} & {$[0.509,0.411]$} & {$[0.191,0.281]$} \\
\hline Sum & {$[4,4]$} & {$[4,4]$} & {$[4,4]$} & {$[4,4]$} & {$[4,4]$} & {$[4,4]$} & {$[4,4]$} & {$[4,4]$} & {$[4,4]$} & {$[4,4]$} & {$[4,4]$} & {$[4,4]$} \\
\hline
\end{tabular}

Table A5. The weighted super-matrix $\otimes \boldsymbol{W}_{w}$.

\begin{tabular}{|c|c|c|c|c|c|c|c|c|c|c|c|c|}
\hline & ES1 & ES2 & ES3 & GS1 & GS2 & GS3 & SS1 & SS2 & SS3 & IS1 & IS2 & IS3 \\
\hline ES1 & {$[0.046,0.068]$} & {$[0.117,0.099]$} & {$[0.115,0.099]$} & {$[0.081,0.088]$} & {$[0.088,0.089]$} & {$[0.080,0.088]$} & {$[0.108,0.098]$} & {$[0.080,0.090]$} & {$[0.138,0.103]$} & {$[0.112,0.098]$} & {$[0.113,0.098]$} & {$[0.110,0.097]$} \\
\hline ES2 & {$[0.130,0.108]$} & {$[0.053,0.076]$} & {$[0.120,0.105]$} & {$[0.118,0.105]$} & {$[0.136,0.110]$} & {$[0.129,0.109]$} & {$[0.123,0.106]$} & {$[0.110,0.101]$} & {$[0.125,0.108]$} & {$[0.118,0.108]$} & {$[0.113,0.103]$} & {$[0.115,0.104]$} \\
\hline ES3 & {$[0.104,0.095]$} & {$[0.109,0.096]$} & {$[0.043,0.066]$} & {$[0.099,0.094]$} & {$[0.074,0.087]$} & {$[0.088,0.090]$} & {$[0.111,0.095]$} & {$[0.152,0.108]$} & {$[0.079,0.088]$} & {$[0.100,0.090]$} & {$[0.104,0.095]$} & {$[0.106,0.095]$} \\
\hline GS1 & {$[0.088,0.088]$} & {$[0.092,0.089]$} & {$[0.119,0.096]$} & {$[0.043,0.064]$} & {$[0.120,0.097]$} & {$[0.106,0.091]$} & {$[0.110,0.090]$} & {$[0.094,0.087]$} & {$[0.078,0.083]$} & {$[0.064,0.080]$} & {$[0.097,0.090]$} & {$[0.092,0.088]$} \\
\hline GS2 & {$[0.061,0.071]$} & {$[0.075,0.076]$} & {$[0.059,0.071]$} & {$[0.115,0.087]$} & {$[0.034,0.054]$} & {$[0.136,0.094]$} & {$[0.045,0.065]$} & {$[0.034,0.059]$} & {$[0.059,0.067]$} & {$[0.058,0.070]$} & {$[0.060,0.070]$} & {$[0.068,0.073]$} \\
\hline GS3 & {$[0.095,0.089]$} & {$[0.077,0.083]$} & {$[0.066,0.081]$} & {$[0.124,0.097]$} & {$[0.127,0.097]$} & {$[0.039,0.062]$} & {$[0.055,0.077]$} & {$[0.082,0.086]$} & {$[0.073,0.082]$} & {$[0.118,0.095]$} & {$[0.083,0.085]$} & {$[0.080,0.083]$} \\
\hline SS1 & {$[0.057,0.064]$} & {$[0.048,0.061]$} & {$[0.041,0.060]$} & {$[0.043,0.061]$} & {$[0.025,0.054]$} & {$[0.039,0.059]$} & {$[0.021,0.044]$} & {$[0.050,0.064]$} & {$[0.085,0.075]$} & {$[0.030,0.054]$} & {$[0.062,0.065]$} & {$[0.065,0.066]$} \\
\hline SS3 & {$[0.081,0.079]$} & {$[0.072,0.077]$} & {$[0.050,0.071]$} & {$[0.065,0.074]$} & {$[0.069,0.076]$} & {$[0.066,0.075]$} & {$[0.092,0.083]$} & {$[0.059,0.073]$} & {$[0.029,0.054]$} & {$[0.067,0.074]$} & {$[0.076,0.078]$} & {$[0.071,0.076]$} \\
\hline IS1 & {$[0.057,0.067]$} & {$[0.058,0.065]$} & {$[0.051,0.065]$} & {$[0.053,0.065]$} & {$[0.040,0.063]$} & {$[0.080,0.074]$} & {$[0.035,0.063]$} & {$[0.084,0.077]$} & {$[0.084,0.074]$} & {$[0.026,0.047]$} & {$[0.058,0.067]$} & {$[0.058,0.067]$} \\
\hline IS2 & {$[0.120,0.102]$} & {$[0.121,0.104]$} & {$[0.120,0.103]$} & {$[0.113,0.102]$} & {$[0.118,0.103]$} & {$[0.091,0.095]$} & {$[0.132,0.107]$} & {$[0.108,0.100]$} & {$[0.108,0.101]$} & {$[0.100,0.098]$} & {$[0.048,0.073]$} & {$[0.117,0.103]$} \\
\hline IS3 & {$[0.102,0.094]$} & {$[0.100,0.094]$} & {$[0.107,0.095]$} & {$[0.091,0.092]$} & {$[0.099,0.093]$} & {$[0.085,0.088]$} & {$[0.126,0.101]$} & {$[0.102,0.094]$} & {$[0.101,0.095]$} & {$[0.090,0.092]$} & {$[0.110,0.097]$} & {$[0.041,0.066$} \\
\hline Sum & {$[1,1]$} & {$[1,1]$} & {$[1,1]$} & {$[1,1]$} & {$[1,1]$} & {$[1,1]$} & {$[1,1]$} & {$[1,1]$} & {$[1,1]$} & {$[1,1]$} & {$[1,1]$} & {$[1,1]$} \\
\hline
\end{tabular}


Table A6. PGRA questionnaires: 11 experts.

\begin{tabular}{ccccccccccccc}
\hline & ES1 & ES2 & ES3 & GS1 & GS2 & GS3 & SS1 & SS2 & SS3 & IS1 & IS2 & IS3 \\
\hline Expert 1 & G & G & G & G & P & M & M & M & M & M & M & VG \\
\hline Expert 2 & VG & G & G & VG & VG & VG & P & G & P & M & VG & VG \\
\hline Expert 3 & G & G & P & M & M & G & M & M & G & M & M & M \\
\hline Expert 4 & VG & VG & G & G & G & G & M & M & G & M & VG & VG \\
\hline Expert 5 & M & G & G & M & VG & M & G & G & G & M & P & G \\
\hline Expert 6 & M & G & M & VG & VG & VG & M & G & M & P & G & G \\
\hline Expert 7 & G & G & G & G & VG & M & M & M & G & M & VG & VG \\
\hline Expert 8 & VG & VG & G & VG & VG & G & G & M & G & M & VG & VG \\
\hline Expert 9 & M & G & G & VG & VG & VG & G & G & M & P & G & G \\
\hline Expert 10 & M & G & G & VG & VG & VG & G & G & M & M & M & M \\
\hline Expert 11 & M & G & P & G & G & G & VG & G & M & M & M & M \\
\hline
\end{tabular}

Table A7. The grey initial decision matrix $\otimes G$.

\begin{tabular}{|c|c|c|c|c|c|c|c|c|c|c|c|c|}
\hline & ES1 & ES2 & ES3 & GS1 & GS2 & GS3 & SS1 & SS2 & SS3 & IS1 & IS2 & IS3 \\
\hline $\begin{array}{l}\text { Sun } \\
\text { Moon } \\
\text { Lake }\end{array}$ & $\begin{array}{l}{[1.818} \\
2.818]\end{array}$ & $\begin{array}{l}\text { [2.182, } \\
3.182]\end{array}$ & $\begin{array}{l}{[1.545} \\
2.545]\end{array}$ & $\begin{array}{l}{[2.273} \\
3.273]\end{array}$ & $\begin{array}{l}{[2.364,} \\
3.364]\end{array}$ & $\begin{array}{l}{[2.091} \\
3.091]\end{array}$ & $\begin{array}{l}{[1.455,} \\
2.455]\end{array}$ & $\begin{array}{l}{[1.545} \\
2.545]\end{array}$ & $\begin{array}{l}{[1.364,} \\
2.364]\end{array}$ & $\begin{array}{l}{[0.818,} \\
1.818]\end{array}$ & $\begin{array}{l}{[1.818,} \\
2.818]\end{array}$ & $\begin{array}{l}{[2.182,} \\
3.182]\end{array}$ \\
\hline $\begin{array}{l}\text { Worst } \\
\text { level }\end{array}$ & $\begin{array}{l}{[0.000} \\
0.000]\end{array}$ & $\begin{array}{l}{[0.000,} \\
0.000]\end{array}$ & $\begin{array}{l}{[0.000} \\
0.000]\end{array}$ & $\begin{array}{l}0.000, \\
0.000]\end{array}$ & $\begin{array}{l}0.000, \\
0.000]\end{array}$ & $\begin{array}{l}0.000, \\
0.000]\end{array}$ & $\begin{array}{l}0.000, \\
0.000]\end{array}$ & $\begin{array}{l}0.000, \\
0.000]\end{array}$ & $\begin{array}{l}{[0.000,} \\
0.000]\end{array}$ & $\begin{array}{l}0.000, \\
0.000]\end{array}$ & $\begin{array}{l}{[0.000,} \\
0.000]\end{array}$ & $\begin{array}{l}{[0.000,} \\
0.000]\end{array}$ \\
\hline $\begin{array}{c}\text { Aspiration } \\
\text { level }\end{array}$ & $\begin{array}{l}{[3.000,} \\
4.000]\end{array}$ & $\begin{array}{l}\text { [3.000, } \\
4.000]\end{array}$ & $\begin{array}{l}{[3.000,} \\
4.000]\end{array}$ & $\begin{array}{l}{[3.000,} \\
4.000]\end{array}$ & $\begin{array}{l}\text { [3.000, } \\
4.000]\end{array}$ & $\begin{array}{l}{[3.000,} \\
4.000]\end{array}$ & $\begin{array}{l}{[3.000,} \\
4.000]\end{array}$ & $\begin{array}{l}{[3.000,} \\
4.000]\end{array}$ & $\begin{array}{l}\text { [3.000, } \\
4.000]\end{array}$ & $\begin{array}{l}{[3.000,} \\
4.000]\end{array}$ & $\begin{array}{l}\text { [3.000, } \\
4.000]\end{array}$ & $\begin{array}{l}{[3.000,} \\
4.000]\end{array}$ \\
\hline
\end{tabular}

\section{References}

1. Pouder, R.W.; Clark, J.D.; Fenich, G. An exploratory study of how destination marketing organizations pursue the sports tourism market. J. Destin. Mark. Manag. 2018, 9, 184-193. [CrossRef]

2. Lee, T.H.; Jan, F.-H. Can community-based tourism contribute to sustainable development? Evidence from residents' perceptions of the sustainability. Tour. Manag. 2019, 70, 368-380. [CrossRef]

3. Musavengane, R.; Siakwah, P.; Leonard, L. The nexus between tourism and urban risk: Towards inclusive, safe, resilient and sustainable outdoor tourism in African cities. J. Outdoor Recreat. Tour. 2020, 29, 100254.

4. Yang, J.-J.; Lo, H.-W.; Chao, C.-S.; Shen, C.-C.; Yang, C.-C. Establishing a Sustainable Sports Tourism Evaluation Framework with a Hybrid Multi-Criteria Decision-Making Model to Explore Potential Sports Tourism Attractions in Taiwan. Sustainability 2020, 12, 1673. [CrossRef]

5. Carr, A.; Ruhanen, L.; Whitford, M. Indigenous peoples and tourism: The challenges and opportunities for sustainable tourism. J. Sustain. Tour. 2016, 24, 1067-1079. [CrossRef]

6. Carneiro, M.J.; Breda, Z.; Cordeiro, C. Sports tourism development and destination sustainability: The case of the coastal area of the Aveiro region, Portugal. J. Sport Tour. 2016, 20, 305-334. [CrossRef]

7. Gössling, S. Tourism, tourist learning and sustainability: An exploratory discussion of complexities, problems and opportunities. J. Sustain. Tour. 2018, 26, 292-306. [CrossRef]

8. Mascarenhas, M.; Pereira, E.; Rosado, A.; Martins, R. How has science highlighted sports tourism in recent investigation on sports' environmental sustainability? A systematic review. J. Sport Tour. 2021, 1-24. (in press).

9. Gkoumas, A. Evaluating a standard for sustainable tourism through the lenses of local industry. Heliyon 2019, 5, 02707. [CrossRef]

10. Asmelash, A.G.; Kumar, S. Assessing progress of tourism sustainability: Developing and validating sustainability indicators. Tour. Manag. 2019, 71, 67-83. [CrossRef]

11. Hsu, C.-Y.; Chen, M.-Y.; Nyaupane, G.P.; Lin, S.-H. Measuring sustainable tourism attitude scale (SUS-TAS) in an Eastern island context. Tour. Manag. Perspect. 2020, 33, 100617. [CrossRef]

12. López-Bonilla, L.M.; Reyes-Rodríguez, M.D.C.; López-Bonilla, J.M. Golf tourism and sustainability: Content analysis and directions for future research. Sustainability 2020, 12, 3616. [CrossRef]

13. Fromel, K.; Kudlacek, M.; Groffik, D. Tourism and Physical Activity Preferences: Development and Sustainability Strategy. Sustainability 2020, 12, 8824. [CrossRef]

14. Cooper, J.A.; Alderman, D.H. Cancelling March Madness exposes opportunities for a more sustainable sports tourism economy. Tour. Geogr. 2020, 22, 525-535. [CrossRef] 
15. Jiménez-García, M.; Ruiz-Chico, J.; Peña-Sánchez, A.R.; López-Sánchez, J.A. A bibliometric analysis of sports tourism and sustainability (2002-2019). Sustainability 2020, 12, 2840. [CrossRef]

16. Yang, J.-J.; Chuang, Y.-C.; Lo, H.-W.; Lee, T.-I. A Two-Stage MCDM Model for Exploring the Influential Relationships of Sustainable Sports Tourism Criteria in Taichung City. Int. J. Environ. Res. Public Health 2020, 17, 2319. [CrossRef]

17. Gil-Alana, L.A.; Figueiredo, O.H.D.S.; Wanke, P. Structural breaks in Brazilian tourism revenues: Unveiling the impact of exchange rates and sports mega-events. Tour. Manag. 2019, 74, 207-211. [CrossRef]

18. Lo, H.-W.; Hsu, C.-C.; Chen, B.-C.; Liou, J.-J. Building a grey-based multi-criteria decision-making model for offshore wind farm site selection. Sustain. Energy Technol. Assess. 2021, 43, 100935.

19. Gabus, A.; Fontela, E. World Problems, An Invitation to Further thought within the Framework of DEMATEL; Battelle Geneva Research Center: Geneva, Switzerland, 1972.

20. Gul, M. Emergency department ergonomic design evaluation: A case study using fuzzy DEMATEL-focused two-stage methodology. Health Policy Technol. 2019, 8, 365-376. [CrossRef]

21. Hsu, W.-C.J.; Liou, J.-J.; Lo, H.-W. A group decision-making approach for exploring trends in the development of the healthcare industry in Taiwan. Decis. Support Syst. 2021, 141, 113447. [CrossRef]

22. Hsu, C.-C.; Liou, J.-J.; Lo, H.-W.; Wang, Y.-C. Using a hybrid method for evaluating and improving the service quality of public bike-sharing systems. J. Clean Prod. 2018, 202, 1131-1144. [CrossRef]

23. Kumar, A.; Anbanandam, R. Analyzing interrelationships and prioritising the factors influencing sustainable intermodal freight transport system: A grey-DANP approach. J. Clean Prod. 2020, 252, 119769.

24. Singh, S.; Misra, S.C.; Kumar, S. Identification and ranking of the risk factors involved in PLM implementation. Int. J. Prod. Econ. 2020, 222, 107496.

25. Rajesh, R.; Ravi, V. Supplier selection in resilient supply chains: A grey relational analysis approach. J. Clean Prod. 2015, 86, 343-359. [CrossRef]

26. Lo, H.-W.; Liou, J.-J. A novel multiple-criteria decision-making-based FMEA model for risk assessment. Appl. Soft. Comput. 2018, 73, 684-696. [CrossRef]

27. Huang, F.-H.; Ye, Y.-J.; Kao, C.-H. Developing a novel Intuitionistic Fuzzy Importance-performance Analysis for evaluating corporate social responsibility in sports tourism event. Expert Syst. Appl. 2015, 42, 6530-6538. [CrossRef]

28. Kapera, I. Sustainable tourism development efforts by local governments in Poland. Sust. Cities Soc. 2018, 40, 581-588. [CrossRef]

29. Paunović, I.; Jovanović, V. Implementation of Sustainable Tourism in the German Alps: A Case Study. Sustainability 2017, 9, 226. [CrossRef]

30. Lasso, A.; Dahles, H. Are tourism livelihoods sustainable? Tourism development and economic transformation on Komodo Island, Indonesia. Asia Pac. J. Tour. Res. 2018, 23, 473-485.

31. Perić, M.; Vitezić, V.; Badurina, J.Đ. Business models for active outdoor sport event tourism experiences. Tour. Manag. Perspect. 2019, 32, 100561. [CrossRef]

32. Lo, H.-W.; Liou, J.-J.; Tzeng, G.H. Comments on "Sustainable recycling partner selection using fuzzy DEMATEL-AEW-FVIKOR: A case study in small-and-medium enterprises". J. Clean Prod. 2019, 228, 1011-1012. 